\title{
Deep structure of the Demerara Plateau: From a volcanic margin to a Transform Marginal Plateau
}

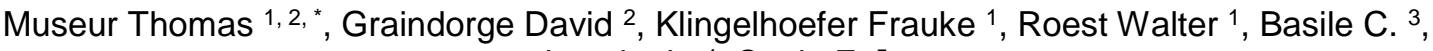 \\ Loncke L. ${ }^{4}$, Sapin F. ${ }^{5}$
}

\author{
1 Ifremer, Centre de Brest, Institut Carnot - Ifremer EDROME, UR Géosciences Marines, BP 70, 29280 \\ Plouzané, France \\ 2 University of Brest, CNRS, IUEM, Plouzané, France \\ ${ }^{3}$ ISTerre, UMR-CNRS 5275, Observatoire des Sciences de I'Univers de Grenoble, Université Joseph \\ Fourier, Maison des Géosciences, 1381 rue de la Piscine, 38400 St. Martin d'Hères, France \\ 4 University of Perpignan Via Domitia, Centre de Formation et de Recherche sur les Environnements \\ Méditerranéens (CEFREM), UMR 5110, 52 Avenue Paul Alduy, 66100 Perpignan, France \\ 5 Total SA, Centre Scientifique et Technique Jean Feger (CSTJF), Avenue Larribau, 64018 Pau, France \\ *Corresponding author : Thomas Museur, email address : thomas.museur@gmail.com
}

\begin{abstract}
:
The Demerara Plateau (offshore Suriname and French Guiana) is located at the junction of the Jurassic Central Atlantic and the Cretaceous Equatorial Atlantic Oceans. The study of its crustal structure is fundamental to understanding its tectonic history, its relationship with the adjacent oceanic domains and to enlightening the formation of Transform Marginal Plateaus (TMPs). This study presents two wide-angle seismic velocity models from the MARGATS cruise seismic experiment, and adjacent composite seismic reflexion lines. The plateau itself is characterized by a $30 \mathrm{~km}$ thick crust, subdivided into three layers, including a high velocity lower crust (HVLC). The velocities and velocity gradients do not fit values of typical continental crust but could fit with volcanic margin or Large lgneous Province (LIP) type crusts. We propose that the, possibly continental, lower crust is intruded by magmatic material and that the upper crustal layer is likely composed of extrusive volcanic rocks of the same magmatic origin, forming thick seaward dipping reflector sequences tilted to the west. This SDR complex was emplaced during hotspot related volcanic rifting preceding the Jurassic opening of the Central North Atlantic and forming the present-day western margin of the plateau. The internal limit of the SDR complex corresponds to the future limit of the eastern margin. The Demerara Plateau would therefore be an inherited Jurassic volcanic margin boarding the Central Atlantic. This margin was reworked during the Cretaceous at the eastern limit of the Jurassic SDR complex, creating the present-day northern transform margin and the eastern divergent margin along the Equatorial Atlantic. This study also highlights the major contribution of thermal anomalies such as hotspots and superposed tectonic phases in the history of TMPs, which share a great number of characteristics with Demerara.
\end{abstract}




\section{Introduction}

Marginal plateaus are defined as submarine ean highs with a flat (or subhorizontal) top, located deeper than the shelf break vith in the continental slope (Mercier de Lépinay et al., 2016). They are often located at the inci. on between two oceanic domains of different ages (Mercier de Lepinay et al., $201 \%$. J ecently, the sub-category of Transform Marginal Plateaus (TMP) was defined, $f, f$ hos marginal plateaus bordered by at least one transform or oblique margin (Loncke et a1., 2019). According to these authors, most of these plateaus are associated with at least on major volcanic event during their evolution. TMPs are therefore geodynamic nodes that $\mathrm{r}$ ave possibly recorded polyphase tectonic and magmatic histories. Their study provides $i_{1}$. 7 rmation on ocean opening processes, break-up conditions, and the thermomechanical eve'ulion of continental margins.

The Demerara Plntea is a transform marginal plateau located offshore South America, on the Fren: Cina-Suriname margin, at the junction between the Equatorial and Central Atlantic (Figur :). Several academic and industrial data sets have been acquired in this region over the past 20 years. The quantity and diversity of these data make it an ideal place to study the formation and evolution of a TMP. Although the surface and shallow subsurface of the plateau have been intensively investigated (Gouyet, 1988; Campan, 1995; Greenroyd et al., 2007; Basile et al., 2013; Pattier et al., 2013; 2015; Loncke et al., 2009 and 2016; Mercier de Lépinay, 2016; Tallobre et al., 2016; Fanget et al. 2020), the deeper part of the plateau, located under a thick sedimentary cover has been little investigated.

The primary objective of this paper is to describe the deep crustal structure of the Demerara Plateau. To address this objective, we adopted two geophysical. Firstly, academic deep penetrating multichannel reflection and wide-angle seismic data acquired during the 
MARGATS (IUEM/Ifremer) oceanographic experiment on the R/V L'Atalante in 2016 were modeled and interpreted. The processing of the wide-angle data results in two velocity models that span the eastern part of the plateau, crossing the eastern divergent edge. The second dataset of Multi-Channel Seismic (MCS) lines includes several sets of deep-penetrating reflection seismic data imaging down to 16 seconds two-way travel time (TWT). The combination of velocity and geometry of the layers allows a robust interpretation and is used to propose the chronology and processes that led to the formation of the plateau.

Figure 1: Bathymetric map of the Demerara Plateau and surrc "'ding area. Location of the seismic profiles are indicated by black and red lines and frac. 'ure ones by white dashed lines. The Southern Limit of the Equatorial Atlantic (SLEA) sep، ratts the Jurassic Central Atlantic southward and the Cretaceous Equatorial Atlantic No."ain northward. The green line underlines the northern tran. fro margin.

\section{Geological context}

About twenty submarine plateau worldwide have been classified as TMPs (Loncke et al., 2019). While some of them hav: h,een extensively studied, such as the Walvis Ridge (Gladczenko et al., 1998; Elliott _+ al., 2009; Fromm et al., 2017; Planert et al., 2017), others remain poorly known, partly ¿'ve s their inaccessibility (e. g. Gunnerus Ridge: Leitchenkov et al., 2008). Their tectonic hisı $y$ is complex since they frequently combine different rifting phases and large mas $\eta_{a_{i}}{ }_{-}$events. Different geological processes have been proposed to explain the evolution of TMPs. For example, the Falklands-Malvinas TMP underwent a volcanic episode during its Jurassic break-up which was associated with the Karoo hotspot province (Barker, 1999; Schimschal et al., 2018, 2019).A second phase of opening in the Lower Cretaceous leading to the creation of the largest transform margin in the world (Loncke et al., 2019), whereas the Hatton-Rockall TMP underwent a phase of volcanic underplating (White et al., 2008, White and Smith, 2009) or the development of a volcanic margin (Welford et al., 2012) during its second opening phase.

Several geological events are involved in the formation of the Demerara Plateau. First, it is connected to the Guyana shield, a vast province extending from Venezuela to Amapá (NE Brazil), which is mostly composed of rocks emplaced during the Trans-Amazonian orogeny 
between 2.26 and 1.95 My in Paleoproterozoic times. It is the western continuity of the western Africa craton providing evidence that South America and Africa were joined within Gondwana before the opening of the Atlantic Ocean (Figure 2e). The opening of the Central Atlantic Ocean is predated by a major magmatic episode corresponding to the Central Atlantic Magmatic Province (CAMP ; Marzoli et al., 1999): a region of intense magmatic activity dated at $200 \mathrm{My}$, extending over 2.5 million square kilometers and expressed in Guyana and Guinea by dense networks of doleritic dykes. The Sierra Leone hot spot may have been associated with the CAMP province before it localized in the Demerara area at the end of the lower Jurassic (Basile et al., 2020).

When rifting that led to the Central Atlantic openisis initiated, the region now occupied by the Demerara Plateau was connected to Florio ? (B thamas) to the NW and to western Africa (Guinea) to the NE (Figure 2d). The centr، 1 Al'antic separates North America and Africa approximately following the hercynian ornot: $v$ from the Newfoundland fracture zone in the north to Guyana-Surinam in the south (K1: igord et Schouten, 1986), and was characterized by a NW-SE opening direction ( $\Gamma$ zure $2 \mathrm{~d}$ ). At that time, the Guinea and Demerara Plateaus formed, the eastern dive-genı margin of the southern Central Atlantic (Figure $2 \mathrm{~d}$ and $\mathrm{c}$ ). It is precisely this pha $f^{\prime}$ lat led to the formation of the western continental

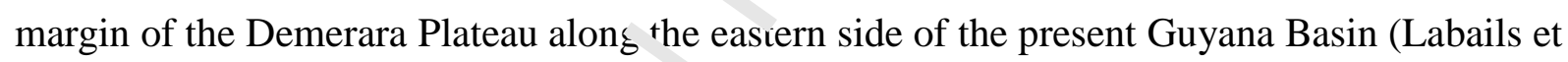
al., 2007) (Figure 2c). This weste $\mathrm{n}$ hrder was oriented perpendicular to the divergent opening direction and separated in vemerara Plateau from the Bahamas Platform (Figure 2b).

Then during upper Tretsceous, the Equatorial Atlantic separated Africa from South America following the race of Panafrican orogeny whose geodynamical models predict a suture offshore northeası Guyana (Figure 2b). Older Jurassic structures were then cut to the north and to the east and the Guinea and Demerara Plateaus separated (Figure 2b). This opening phase is complex, with a probably change of the opening direction around the Albien-Aptien (Campan, 1995). Studies of oceanic fracture zones show a dextral shift at the paleo-limit between the Demerara Plateau and the Guinean Plateau, highlighting the existence of a transform or oblique fault (Campan, 1995) (Figure 2b). Kinematic reconstructions (Moulin et al., 2010) propose the eastern margin of Demerara as a divergent margin (Figure $2 \mathrm{~b}$ and $\mathrm{a}$ ), which seems to be confirmed by large normal faults visible in the seismic data, forming large basins filled by Cretaceous sediments (Sapin et al., 2016). To summarize, the northern border of the Demerara Plateau is a transform margin whereas the eastern border form a divergent margin of the western Equatorial Atlantic. 
After the Mid-Cretaceous, only vertical movements, recorded by sedimentation, affected the plateau. A regional shallow water (wave-cut) or subaerial major erosion phase during the Upper Albian led to a discordance between ante-Albian and younger sediments, visible on the seismic lines (Basile et al. 2013). The Demerara Plateau has been subsiding since then, although experiencing several large vertical movements (Sapin et al., 2016). Inclination of the sedimentary layers indicates that the plateau has undergone several minor tilting phases (Gouyet et al., 1988).

Figure 2: Geodynamic reconstructions (South America fixed) nt the Central and Equatorial Atlantic (rotation parameters from Müller et al., 2016): a) Pre ${ }^{\text {ov } t}$ day, Demerara (D) and its conjugates: Guinea Plateau $(G)$ and Bahamas (B), FZ: I ar ure Zones, SLNEA : Southern Limit of the Northern Equatorial Atlantic; b) Recons ru twon at $80 \mathrm{Ma}$; c) Reconstruction at $120 \mathrm{Ma}$; d) Reconstruction at $160 \mathrm{Ma}$; d) Reconstruc ${ }^{+} \mathrm{o} \cdot$ at $200 \mathrm{Ma}$. PFC Panafrican Chains.

\subsection{The superficial structure of the $\mathbf{L}+\mathrm{m}$ erara Plateau}

Previous studies (Loncke et al., ¿ 09; Pattier et al., 2013 and 2015) using high resolution seismic and bathymetric $a_{a}{ }^{+} \mathrm{z}$ prove the existence of series of stacked Mass Transport Deposits (MTDs) or deep-erted collapses along the plateau that have recorded a history of large-scale slope fail'ı`s. Those studies also reveal the existence of sets of normal faults that provide possible $\mathrm{r}$ atı yays for upward fluid migration through the sedimentary series and the uppermost $\wedge^{\wedge} \mathrm{L}$. The development of the MTDs results from the combination of the presence of fluid ${ }^{1}$ pressure, the internal geometry of the margin, the stratigraphic

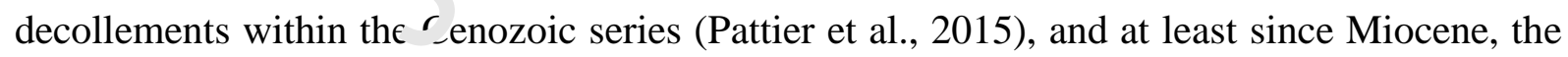
action of deep bottom thermohaline currents regularly eroding the slope (Fanget et al., 2020).

Within the plateau, E-W to WNW-ESE trending folds related to a period of transpression dated latest Aptian - early Albian (Benkhelil et al., 1995; Mercier de Lépinay, 2016) are sealed by a well imaged regional unconformity (Basile et al., 2013). Some of these folds are cut by normal faults related to the transform margin formation during the Mid/Late Albian. The end of the shortening is probably related to a plate kinematic reorganization around $105 \mathrm{My}$ ago, that modified the strain field in the vicinity of the transform fault and remained active until the Upper Cretaceous (Benkhelil et al., 1995; Basile et al., 2013). 
Along the transform margin, the northern slope provides a useful cross section into the deeper part of the plateau outcropping at the seafloor. Dredges (DRADEM cruise; Basile et al., 2017) along the transform margin have recovered magmatic rocks: fresh basalts, rhyolites, trachy-basalts and basaltic trachy-andesites. Rhyolites were dated to $173.4 \pm 1.6 \mathrm{Ma}$ (Basile et al., 2020). All samples share similar patterns in trace elements (Basile et al., 2020). They are Light Rare Earth-enriched, and present positive anomalies in $\mathrm{Nb}, \mathrm{Ta}, \mathrm{Zr}$ and $\mathrm{Hf}$, typical of ocean island basalts (OIB), and thus indicate a possibly hotspot-related magmatic event. These analyses support the hypothesis of a volcanic origin of the plateau (Reuber et al., 2016).

\subsection{The deep structure of the Demerara Platea.}

The deep structure of the Demerara Plateau was firsı imaged by wide-angle seismic data, along a $500 \mathrm{~km}$ SSW-NNE oriented line from the $\mathrm{c}$ 'st o the deep oceanic domain through the ocean-plateau transition and the Cretaceous $t^{*}$ ws sform or oblique margin (Greenroyd et al., 2008; see location of this line on Figure 10). Kasu: on variations in Moho depth and velocity structure, the authors propose three $\mathrm{d}$ ffe ent domains: a continental domain, a thinned continental crust plateau domain, and a well-defined oceanic domain. The continental nature of the plateau itself was proposed $d v \_$the absence of unequivocal lateral velocity variations between the shelf and the plateau « mains (Greenroyd et al., 2008).

The Demerara Plateau was also imaged by several deep seismic reflection surveys for industry purposes (Reuber c: al , 2016). Interpretations of the MCS data reveal the existence of distinct fan-shape ge los ical units composing parts of the crust, increasing in thickness from east to west. The upı er part of the crust is composed of a $20 \mathrm{~km}$ thick layer comprised of a large complex of superimposed wedges thickening towards the Jurassic margin (Reuber et al., 2016). Based on the observed geometry, these sequences were proposed to be Seaward Dipping Reflectors (SDRs; Reuber et al., 2016).

Below these units, the deepest unit is highly deformed and deeply affected by what are likely be magmatic intrusions (Reuber et al., 2016). Alternatively, this might also represent a geological unit pre-dating the opening of the central Atlantic and including a basement composed in part of meta-sediments corresponding to the Guiana Shield (Precambrian craton) (Mercier de Lepinay, 2016). Reuber et al. (2016) proposed the existence of a "volcanic igneous crust" formed by magmatic processes during the Jurassic opening in relation to the 
SDR wedges formation. These elements have led to reinforce the hypothesis of a crust of volcanic origin of the Demerara Plateau rather than continental as proposed by Greenroyd et al. (2008).

One of the main objectives of this study is to add new elements to the debate on the nature of the Demerara Plateau using deep-sounding seismic reflection and new wide-angle seismic data.

\section{Acquisition and processing of the seismic ' lata}

\subsection{The MARGATS cruise}

The MARGATS deep seismic cruise took pla « n the R/V L'Atalante from October $20^{\text {th }}$ to November $16^{\text {th }} 2016$, offshore French Guiana an suriname. We used 80 ocean-bottom seismometers (OBS) for 171 deployments. ' $h y$ s were deployed along four combined reflection and wide-angle seismic profiles ' ${ }^{2}$ ig. re 1). The seismic source consisted of a 6500 inch $^{3}$ airgun array fired every 60 seconds , ', ulting in a $150 \mathrm{~m}$ shot spacing. Seismic data were recorded by a $3 \mathrm{~km}$-long Sercel $\operatorname{dig}_{\mathrm{\imath}} \mathrm{\imath}$ streamer (480 channels). This paper presents two coincident reflection and wide-angl $\varepsilon_{21}$, nic lines on the eastern part of the plateau: the NESW MAR01 (56 OBS) profile cossing the eastern divergent margin at its intersection with the northern transform margin a. $\cdot$ the WNW-ENE MAR02 (37 OBS) profile intersecting the eastern divergent margin. A ${ }^{11}$ ()BS data were corrected for time drift and spatial drift that occurred during the tes ent to the seafloor using direct arrivals and converted to SEGY format according to seism ic shots. The OBS data is of extremely high quality with offsets of usable arrivals of up to $200 \mathrm{~km}$ on some instruments (Figure 3, Figure 4, Figure 5 and Figure 6). The arrivals from the different crustal layers (upper, middle, and lower crust) were identified by their apparent velocities, amplitudes and arrival times. The picking of all phases was undertaken, where possible, on unfiltered data. However, along noisy parts of the sections a bandpass filter with the corner frequencies of 3-5-18-24 Hz was used. Based on these identifications, the wide-angle seismic sections can be separated into two main groups (examples are shown in Figures 3, 4, 5 and 6). The first group includes stations located in shallow water depths on the plateau (Figure 3 and 6 for Profile 1 and 2, respectively) and are therefore characterized by numerous multiple arrivals and a relatively high noise level, 
requiring the use of bandpass filtering. The arrivals of the Moho reflection (PmP) and upper mantle turning rays $(\mathrm{Pn})$, if present, can be typically identified at offsets larger than $70 \mathrm{~km}$, indicating a thick crust in this region. Only a few and short arrivals from sedimentary layers were recorded. The second group comprises the stations situated in the oceanic domain (Figure 4 and 5 for Profile 1 and 2, respectively). Here, the PmP and Pn phases arrive at shorter offsets, due to a thinner crust and a Moho situated at a shallower level. The sedimentary phases are longer for the stations located along the sedimentary basins. Data from the seismometers located along the slope of the plateau are characterized by a large asymmetry with arrivals belonging to the first group towards the plateau and the second group towards the ocean. Data from the seismometers located along the slope of the plateau are characterized by a large asymmetry, with arrivals from the pl tea on the one hand, and from the ocean on the other. The reflection seismic data with a $C D$ ? spacing of 6.25 meters and a 22 fold coverage were first quality controlled. They we : pre-processed on board using the SolidQC software from Ifremer and processing $\mathrm{w}_{c} \mathrm{c}$ completed ashore using Geovation software (CGG). The processing included filteri $x$. deconvolution, NMO correction, stacking, velocity analysis, and time migration.

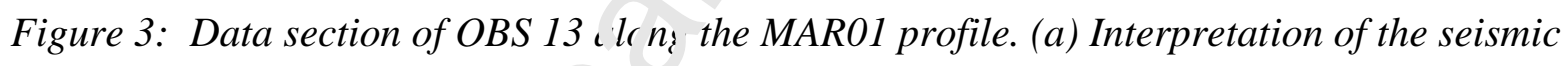
section with annotation of each denified phases: sediment layers (Sed1, Sed2), Upper crust (Uc), Middle crust (Mc), Lowe * crust (Lc), and Moho reflection (Pmp). (b) Uninterpreted seismic section. (c) Syntritir arrivals calculated from the final velocity model MARO1.

Figure 4 : Data section of OBS 32 along the MARO1 profile. (a) Interpretation of the seismic section with annotation of each identified phases (same legend as Figure 3; Mantle refraction $(P n))$. (b) Uninterpreted seismic section. (c) Synthetic arrivals calculated from the velocity model.

Figure 5: Data section of OBS 14 along the MARO2 profile. (a) Interpretation of the seismic section with annotation of each identified phases (same legend as Figure 2). (b) Uninterpreted seismic section. (c) Synthetic arrivals calculated from the velocity model MARO2. 
Figure 6: Data section of OBS 29 along the MAR02 profile. (a) Interpretation of the seismic section with annotation of each identified phases (same legend as Figure 3). (b) Uninterpreted seismic section. (c) Synthetic arrivals calculated from the velocity model MARO2.

Wide-angle data were modeled using the RAYINVR for 'ard modelling software (Zelt \& Smith, 1992). The resulting models comprise discrete layє s d fined by depth and velocity nodes. During the modeling process, the theoretical arrivi is $t_{1}$ m a two-dimensional velocity model were calculated and the model was changed to fin the theoretical arrival times with the picked travel-times from the OBS sections. Addition. ${ }^{1}{ }^{1} \mathrm{y}$. n parts of the model a damped least square inversion has been used to improve the $\mathrm{fi}^{+}$(?elt $\&$ Smith, 1992). The superficial layers (from the seafloor down to the top of the crus ) wae further constrained by bathymetric data and the coincident MCS data. We user a ninimum structure/parameter approach to avoid inclusion of structures unconstrained by the data and gravity modeling to test the broad structure of the velocity models.

\subsection{Error estimation}

The quality of the fit $s$ indicated by the RMS (root-mean-square) travel time residual for all phases of each arri al. A total of 24074 travel-time picks were used forprofile MAR01 and 14218 for MAR02. The resulting RMS travel-time residual is $128 \mathrm{~ms}$ for MAR01 and $137 \mathrm{~ms}$ for MAR02. RMS errors for all phases are listed in Table 1. The quality of the final velocity model was tested by several methods: gravity modelling, synthetic seismogram calculations using the finite difference modelling code from the Seismic Unix Package (Stockwell, 1999; Stockwell \& Cohen, 2003), and a Monte-Carlo inversion (Loureiro et al., 2016). 
The model resolution can be assessed by the number of rays passing through each velocity node (Figure 7c and 7f). It is therefore dependent on the number of velocity nodes in each layer (Figure 7a and 7d). A node is considered to be well constrained at values larger than 0.5 in the resolution (Figure $7 \mathrm{c}$ and $7 \mathrm{f}$ ). The ray density shows the number of rays in each cell of the velocity model (Figure $7 \mathrm{~b}$ and $7 \mathrm{e}$ ).

Figure 7: Uncertainty calculation on MARO1 and MARO2 velocity models. ( $a$ and d) Position of each layer, with the nodes. ( $b$ and $e$ ) Hit-count for velocity ( $g$ : Ided and colored). ( $c$ and $f$ ) Velocity resolution. Only the constrained ar as a e colored.

In the MAR01 model, we observe that the resolution is s at far cory in the sedimentary part, as well as in the upper crust and the middle crust (Figu $\sim{ }^{7} \mathrm{c}$ ). The terms "upper", "middle" and "lower" crust refer only to an organization (crust diviat into three layers) and do not refer at this stage to geological concepts. Less well con itrai led areas are: 1) the lower crust between 100 and $230 \mathrm{~km}$ model distance at a dep${ }^{t^{2}}$ - on $? 6$ to $31 \mathrm{~km}$, and 2) the upper mantle (Figure 7e). The MAR02 model is well constran $\mathrm{d}$ along most of the profile, even for the deeper layers (Figure 7f). However, a small part of the lower crustal body is very poorly covered by seismic rays between 120 and $150 \mathrm{~lm}$. . Jdel distance at 12 to $18 \mathrm{~km}$ depth. The thinning of the lower crustal layer is related o a significant decrease in resolution and the small number of hits related to the geometry. Then, the lowermost part of the crust appears poorly resolved as ray-paths are complicate. a id arrivals are perturbed by two highly irregular interfaces (Figure 7c).

The synthetic so mograms (Figure 3c, Figure 4c, Figure 5c and Figure 6c) provide additional constraints for velocity gradients of all layers. The input velocity model was calculated from the $25 \mathrm{~m}$ lateral and $10 \mathrm{~m}$ depth intervals sampling of the forward velocity model. Overall, along both profiles, the synthetic seismograms favorably reproduce the amplitudes and arrival times of the OBS data, showing that the velocity models take into account the majority of the observed phases (Zelt, 1999).

Our error analysis diagrams estimate model uncertainty (Figure 8). These figures were based on simulating the same modelling process, but on models with systematic variations of velocity and depth of crustal layers. The result is a diagram showing the relative RMS error, as a function of depth, speed, and the number of points used, for a single phase. The final 
velocity models are clearly positioned in the well-constrained part of the model (zone where the RMS is minimal) and describe a maximum number of travel times picks. We carried out these simulations for the middle crust and Moho phases of each velocity models as the sedimentary layers are additionally constrained by the MCS data (Figure 8). The results show that the current models (black cross in Figure 8) are located in the best-constrained areas (minimum RMS, with little variation in velocity and depth, and maximum number of points used). These diagrams show that the error range is small: $+-0.2 \mathrm{~km} / \mathrm{s}$ (Figure 8). For the depth, the error range for the middle crust is relatively small, around $0,5 \mathrm{~km}$. According to the number of point used, the error range at the Moho is around +0,4/-0,4 km for MAR01 and $+0.6 /-0.4 \mathrm{~km}$ for MAR02 (Figure 8).

Figure 8: Velocity anomaly diagrams for the "Mir" in c. ust" and "Moho" phases of the MARO1 and MAR02 velocity models. The horizonta axs sepresent velocity perturbation s and the vertical axes depth perturbations. The color; rep.esent the RMS error resulting from these perturbations. The black contours repr sf n. the number of points explained by the calc!'atıu.

\subsection{Gravity modeling}

As densities and seismic elc rities are proven to be well correlated, the calculation of

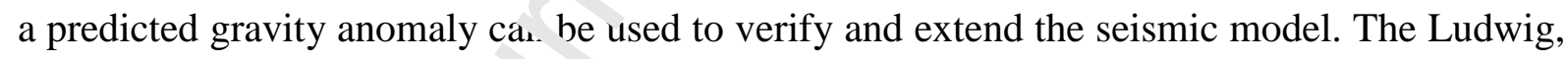
Nafe \& Drake law (Ludwig at a ., 1970) was used to convert seismic velocities into densities. Then, polygons of constant density along each modeled layer were constructed with the "Gravmod" software (Zeı, 1999). The predicted anomaly calculated from the gravity model and derived from the velocity model can then be compared to the free-air gravity anomaly obtained from satellite altimetry (Sandwell \& Smith, 1997).

Figure 9: (A) Free-air Gravity map (Sandwell \& Smith, 1997) used to localized the two profiles. (B) MARO1 and (C) MAR02 profiles, gravity model calculated from the gravity model and derived from the velocity model (red line). Gravity anomaly extracted from free-air anomaly (black line) (Sandwell \& Smith, 1997). The dotted black lines represents an error margin of $\pm 5 \mathrm{mGal}$. In red, location of the 4 OBSs data shown in Figure 2,3,4 and 5.In black the first and last $O B S$ of the lines. 
The fit between the predicted density anomaly and the measured anomaly is good for profile MAR01 (Figure 9B). The region at $250 \mathrm{~km}$ model distance is particularly well reproduced. Most of the modeled values are included in an acceptable error margin of \pm 5 mGal. Nevertheless, a notable difference in trend exists around $200 \mathrm{~km}$ of model distance, where a more pronounced negative anomaly could not be modelled (the difference reaches about $30 \mathrm{mGal}$ maximum). The overall gravity map (Figure 9A) supports our suggestion that this difference may be explained by a local 3D effect, as the profile is slightly offset from a local gravity anomaly at this location (Figure 9A and B: near the OBS 27). There is another difference between 260 and $350 \mathrm{~km}$ in this MAR01 profile. It is difficult here to obtain a good fit because this area probably correspond to the location of trars. ${ }^{\text {. }}$ rm oceanic faults resulting in a heterogeneous area with potentially massive lateral varia ion in the crust. Consequently, we also attribute this misfit to 3D effects. For profile I IAK 72 the difference between the curves is relatively constant along the profile (all includt. ${ }^{3}$ or very close to the $\pm 5 \mathrm{mGal}$ error margin), and the trends are similar (Figure 9A). nverall, the two gravity models are satisfactory and confirm the robustness of the ve'v ity models.

\subsection{Seismic reflection data}

The second set of data used in this s ur.y was provide available by Total SA. It consists of approximately 120 high-penetraı $\urcorner n$ reflection seismic profiles acquired by Fugro, CGG and ION (Figure 10). These data re ecorded respectively up to 12,8 and 16 seconds two-way travel time (TWT).

Figure 10: Bathymetric map of the Demerara Plateau. The coloured lines correspond to reflection seismic profiles. Each colour corresponds to a specific dataset: in red ION GXT data with $16 s$ (TWT) recording time, in blue CGG data with 8 s (TWT) and in green Fugro data with $12 s(T W T)$. The location of the two wide-angle models is indicated by orange lines. The two composite lines used are indicated in black (BB') and purple ( $\left.A A^{\prime}\right)$. The location of the previous velocity model (from Greenroyd et al., 2007) and the well FG2-1 (described by Mercier de Lépinay et al., 2016) is also shown

The age and nature of the different units is partially constrained by well data (FG2-1 drill described in Mercier et al., 2016; location on Figure 10). 


\section{Results}

\subsection{Wide-angle seismic data}

The MAR01 velocity model is $410 \mathrm{~km}$ long (56 OBS), the MAR02 profile is $270 \mathrm{~km}$ long. They include seven layers: the water column, two sedimentary layers, three deep layers, and the mantle layer. The water velocity on both profiles was set to $1.51 \mathrm{~km} / \mathrm{s}$ based on the first reflection arrivals in the OBS data. Two sedimentary layers were modeled along both profiles with a variable thickness between 1-2 km. Based on crustal velocities and layer thicknesses, the final velocity models were divided into thre. domains, plateau, transition zone and oceanic domain (Figure 11).

Along both MAR01 and MAR02 lines, the deep 1.yer have a combined thickness of around $25 \mathrm{~km}$. The first two deep units have velocities arying from $4.50 \mathrm{~km} / \mathrm{s}$ at the top to $7.00 \mathrm{~km} / \mathrm{s}$ at the base. These two layers differ in velc itie, and velocity gradients, with higher gradients in the upper layer. The deepest unit (I nwer unit) above the Moho has velocities between 7.20 and $7.60 \mathrm{~km} / \mathrm{s}$, and an average $\mathrm{th}_{.}{ }^{-1}$ ness between $5 \mathrm{~km}$ (MAR01) and $7 \mathrm{~km}$ (MAR02). On line MAR01, this thickners of $5 \mathrm{~km}$ decreases toward the northeast, until model distance $230 \mathrm{~km}$, where it pinches out

On MAR02 the crustal thi ${ }^{\prime} n \epsilon^{-}$decreases toward the southeast from $31 \mathrm{~km}$ to $10 \mathrm{~km}$ without an associated lateral vflocivy change, so the gradients increase towards the southeast. The Lower unit decreases in th- -kness in the same direction. Along profile MAR01 the depth of the top of this unit is res, tively constant; on MAR02 the top shallows from 21 to $12 \mathrm{~km}$ depth. The unit pinches , 'It at the junction with the oceanic domain, at around model distance $160 \mathrm{~km}$.

In the oceanic domain, the crustal layers are around $5 \mathrm{~km}$ thick along both profiles, which is thinner than in the two other domains. Here, no high-velocity lower unit could be identified and the crust directly overlies the mantle. Although the crust here is slightly thinner $(\sim 5 \mathrm{~km})$ than the mean thickness of oceanic crust, the velocities and velocity gradients are in good agreement with an oceanic origin of the crust (White et al., 1992).

Figure 11: MAR01 and MAR02 final velocity models contoured at a $0.25 \mathrm{~km} / \mathrm{s}$ interval. Shaded areas correspond to the region constrained by ray-tracing. The colour indicates the 
velocity of the P-wave. The different domains are indicated at the bottom by colored areas: the Plateau domain in orange; the transition domain in yellow and the oceanic domain in blue.

\subsection{MCS data and interpretation of composite MCS-WAS lines}

Using the available MCS dataset, we built two composite lines that are partly coincident with our two velocity models (Figure 10). Composite profile BB' is a combination of several seismic reflection lines (Figure 12) and spans the plateau from its western margin to its northeastern margin, where it is approximately coincident with time converted wide-angle velocity model MAR01. Composite profile AA' is also a cnmı 'nation of several seismic reflection lines (Figure 13) and covers the plateau from is . sorthwestern margin to its southeastern margin where it is approximately coinciden+ w th time converted wide-angle velocity models MAR02. As this study focuses on th $\therefore$ 'ep structures, along these composite profiles, all the units above the Albian regional erosion. surface are considered as one single post-Albian set. Seismic facies and geometric $r$ li a ns between the different units help us in advancing an interpretation of the compo ${ }^{*}:$ ines completed by coincident velocity models. The plateau and its adjacent areas can be $\therefore:$ vided into three sets: the plateau domain itself, the western margin and adjacent oceanic c'mmain and the north eastern and eastern margins and adjacent oceanic domains.

Figure 12: Composite profile 'R'. Composed of MCS data in the west and combined wideangle and MCS data in tho ea .. The MARO1 velocity model is visible on the upper profile. Ovr. . 'e r. of seismic data from Reuber et al, 2016.

Figure 13: Composite " ofiles AA', composed of MCS data in the west and combined wideangle and MCS data in the east. The MARO2 velocity model is visible on the upper profile.

- The plateau domain

The plateau domain, clearly imaged by composite lines BB' (Figure 12) and AA' (Figure 13), is affected by a major erosion surface (Basile et al., 2013; Fanget et al., 2020) at the base of the post-Albian units. Below the unconformity, a thick lower Cretaceous unit is observable (between 1 and $2 \mathrm{~s}$ TWT) (Figure 12and Figure 13). The unit is divided into two distinct subsets: the lower located on the western part of the plateauis affected by numerous normal faults toward the margin (related to major slope instabilities). The second subset corresponds 
to a wide younger basin truncated at its top, thinning toward the northeastern and eastern margins and showing several compressive faults in its deep center related to long wavelength folds (Figure 13). The northwestern side of the basin (Figure 13) shows numerous extensive faults cutting the post-Albian units, highlighting a possibly local minor post-Albian extensional phase.

Below the Cretaceous unit lies a unit with strong amplitude facies identified as a Jurassic carbonate platform in the west of the plateau in well FG2-1 described in Mercier et al., 2016.

This Jurassic layer thickens westward and northward reaching its maximum thickness at the location of the outer slope break of the plateau. To the ust, the Jurassic unit clearly thins until it pinches out at the eastern edge of the plateau or line AA' (Figure 13) and in the middle of the plateau on line BB' (Figure 12). Some of t e extensional faults from the Cretaceous rifting either cross over the Jurassic unit or ro ${ }^{+}$within it. The base of the Jurassic sequence is often a clear erosional surface.

Underneath these Jurassic sediments, wi superposed fan shaped bodies with relatively continuous and high amplitude re.c ecturs are observed. Regardless the nature of these units, they present a typical geom.trv of Seaward Dipping Reflectors (SDRs), dipping westward, and will be described witl this terminology. The entire sequence is divided into 3 units: lower SDRs, upper SDRs 1 a id ? (rigure 12 and Figure 13). Upper SDRs 1 and 2 are differentiated by their extension tw vards the west and by internal limits observed on the seismic reflection data. To the ast, these units pinch out on older units (Figure 12 and Figure 13). The base of these unit cor esponds to east-dipping surfaces on which internal reflectors seem to stop (Figure 12 and Figure 13). On lines AA' and BB' the boundary between upper SDRs and lower SDRs c incides with the top of the middle crust defined in velocity models (Figure 11). This provides a velocity range between 4.5 and $6 \mathrm{~km} / \mathrm{s}$ for upper SDRs, and between 6 and $7 \mathrm{~km} / \mathrm{s}$ for lower SDRs. However, towards the margins, this limit no longer concurs: the SDR bodies thin towards the east while the velocity layers maintain similar thickness, raising the question of velocity variations within these bodies. In the SDRs and below, velocities appear to be depth-dependent, and not correlated with stratigraphic units.

The distinction between SDRs layers and the underlying unit, unit A, is based on a change in seismic facies from continuous and powerful reflectors to rather chaotic facies intermittently maintaining locally strong amplitudes that may correspond to magmatic intrusions (dikes, sills). The limit between SDRs and Unit A is not detectable in the velocity models. 
Below the previously mentioned units, we observed two laterally adjacent deep layers. On the one hand, in the western part of the plateau, we observed (only in MCS data) the Lower Unit 1 (Figure 12 and Figure 13). This body is marked by a chaotic and very poorly reflective facies. On the other hand, in the eastern part of the plateau, the velocity models image the Lower Unit 2 (Figure 12 and Figure 13), presenting velocity values from 7.2 to $7.6 \mathrm{~km} / \mathrm{s}$ (Figure 10). These units are about $2 \mathrm{~s}$ TWT thick (Figure 12 and Figure 13). Due to the lack of deep data in the centre of the plateau, no obvious connection can be proved between these two units.

- The Western margin of the plateau and the Jurassic ( entr ll Atlantic adjacent oceanic domain

The post Albian units above the Albian unc niv rnity definitely seal most of the deformation expanding over the western margin ard he central Atlantic oceanic domain. Only a few extensional faults below the actual $c$ at $\mathrm{r}$ western slope of the plateau cross the Late Albian unconformity and affect the $1 r{ }_{n}{ }^{2} s^{\prime}$ 'evels of the Post-Albian unit.

The Cretaceous unit is characterized $: v$ major west dipping extensional faults over the inherited topography of the Jurassic ca.honate platform (well imaged on Figure 12). On line AA' (Figure 13), the Cretaceous uni f or is a bulge below the base of the actual western slope of the plateau probably correst $\cdot$ nd $_{1} \mathrm{~g}$ to the distal domain of the gravity-driven slide of Cretaceous series. Then the re ${ }^{\prime}{ }^{\prime}$ ceous unit thins westward over the Jurassic unit and outer SDRs on line BB' and over $h^{-}{ }^{-}$' urassic unit and Jurassic oceanic crust (line AA'; Figure 13).

The Jurassic uni, niser ts a major thickness decrease below the actual slope clearly controlled by fault-relate'. slope failure on line AA' (Figure 13). The position of the slope seems to have been stable since Jurassic time when the westward extend of the carbonate platform was already a major slope break (line BB', Figure 12). On line AA', a major (possibly volcanic) body is located within the Jurassic unit below the actual slope and above the eastern edge of the outer SDRs unit (Grey body on line AA': Figure 13). Then the Jurassic unit covers the outer SDRs unit toward the oceanic domains with a rather constant $\sim 1 \mathrm{~s}$ thickness. Further west at the boundary with the obvious oceanic domain, the unit is deposited in a graben type structure where it reaches $3 \mathrm{~s}$ TWT on line BB' (Figure 12). This structure seems to clearly determine the limit between the Jurassic oceanic domain and the outer SDRs sitting on top of the western enigmatic margin crust (western continuity of Unit A). 
The deeper part of the western margin toward the oceanic domain is characterized by the end of Upper SDRs 1 and 2, but in terms of acoustic and geometric characteristics, a similar unit is located in the continuity of these units in the transitional zone. We called this unit "Outer SDRs" because of its location outside the plateau domain. It is thinner than similar fan-shaped units in the plateau domain (about 1-2 seconds TWT; Figure 12 and Figure 13). Its location corresponds to an area with significant change in Moho depth, which deepens from 11 seconds TWT (west) to $\sim 14-15 \mathrm{~s}$ TWT below the plateau. The outer SDRs lie above the westward continuity of Unit A, which is marked by a more chaotic facies with scattered but laterally organized strong amplitudes.

At depth, below the western margin, the Lower Unit 1 is clca "ly imaged only in line BB'. This unit thins toward the west. The outset of the Jurassic oce inic crust is defined at the eastern border of Outer SDRs unit and Lower Unit 1, also corı ssponding to an area where the Moho flattens (Figure 12 and Figure 13).

Finally, the western margin and the plateau doı ${ }^{2}{ }_{1.1}$ form a wide $\sim 300 \mathrm{~km}$ coherent structure from the oceanic Jurassic crust to the o' ut , crustal part without SDRs to the east.

- The northeastern and eastern margins of the plateau and the Cretaceous Equatorial Atlantic adjacent oceanic do a

The Albian unconformity is relaively difficult to follow toward the northeastern and eastern margin transitional dcmai $\eta$. Its position is uncertain; subsequently it is challenging to precisely define the part ot $h f$ cretaceous units that may be syn-cretaceous rifting phase. However, it is clear ti. 't i i $^{+}$le st part of the ante Albian units are syn-cretaceous rifting phases. These units form fan sh ped basins controlled by mostly east dipping normal faults. The Jurassic unit is very thin or absent in this area and the facies do not fit with the carbonate platform described to the west (Figure 12 and Figure 13).

The western limit of the eastern transitional zone is defined at the location of the slope break, which also coincides with the eastern limit of the upper and lower SDR units (Figure 12 and Figure 13). The base of the SDR complex still cannot be identified on the coincident wide-angle velocity models. Eastward of this point, Unit A is located below post Jurassic sedimentary units, including the post Albian units.

At depth, below Unit A, we find the eastern and northern part of Lower Unit 2. In the northern margin, the thickness, around 1-2s (TWT) is lower (Figure 12) than in the eastern 
margin where Lower unit 2 is 2-4s-thick (TWT) (Figure 13). These units end before the limit with the Cretaceous oceanic domain further east. It should be noted, however, that the thickness of Lower Unit 2 increases (from 2 s to 3-4 s TWT) at the eastern margin, compared to its thickness in the plateau domain.

Finally the northeastern and eastern margins appear as relatively narrow transitional domains $(<120 \mathrm{~km})$ with no evidence of superficial volcanic facies or units comparable with previously identified SDRs for the western margin.

\section{Discussion}

This study presents two new velocity mode's ac oss the Demerara Plateau, complementing the one published by Greenroyd et $\cdots$ (2007). Located to the east of the previous work, our models are coherent in terms if velocities and units thicknesses. Nevertheless, the number of OBS and their pov er ${ }_{\iota} 1$ shots allow us to image deeper with an increased resolution. We identify a new $\operatorname{set}_{\mathbf{r}}$ unit: the Lower unit, the top of which can correspond to the Moho interpreted by $\mathcal{I}^{r}$-enroyd et al. (2007). Additionally, Reuber et al. (2016) demonstrated the presence of $\mathrm{t}_{\mathrm{L}}$ : $\mathrm{ck}$ SDRs in the western part of the plateau. Mercier et al. (2016) also suggest the presenc : ภ SDRs bodies, thinning towards the eastern margin. Therefore, our correlation betwe $\_n$ this velocity models and reflection seismic profiles provide significant additional constrain . on these SDRs in terms of physical properties (velocities, densities), geometry (thickn sse ; different internal units, top and base of the complex, lateral extensions). In this se ${ }^{\wedge}$ tic $\eta \mathrm{w}$ : discuss the nature and deep structure of this plateau, our results (velocity models and cor tposite lines) will be compared in terms of crustal velocities and geometries with different objects such as other TMPs (the Walvis TMP, the Faroe Bank, the Falklands-Malvinas TMP), volcanic margins (the Pelotas, SE Greenland and Namibian margins) and a LIP-type oceanic plateau (the Agulhas Plateau). The aim is to unequivocally clarify the nature of the Demerara Plateau, its structure and limits, and its formation.

\subsection{The deep structure of the Demerara TMP}

According to our results, the deep crustal structure of the Demerara Plateau consists of three layers (SRDs, Unit A, Lower unit). Using composite lines, we can correlate velocities 
values to better characterize each of these units (Figure 12 and Figure 13). The upper most set (the upper part of the crust), present in the entire plateau domain, is made of SDR packages, which is coherent with previous studies (Reuber et al., 2016; Mercier et al., 2016). In the literature, SDRs are proposed to be composed of varying mixtures of subaerial volcanic flows, volcanoclastic and non-volcanic sediments (Okay et al., 1995; Menzies et al., 2002). This set is divided in two sub-units: Upper SDRs (corresponding to the upper crust in velocity models) and Lower SDRs (corresponding to the upper part of the middle crust in velocity models). Different velocities characterize these two parts: the Upper SDR unit shows relatively low velocities (between 4.5 and $6 \mathrm{~km} / \mathrm{s}$ ) with a marked depth gradient, while the Lower SDRs have higher velocities (between 6 and $7 \mathrm{~km} / \mathrm{s}$ ) and a sma. ${ }^{1} \mathrm{er}$ depth gradient. Higher proportions of sediment in the upper body can explain t is (ifference, as Paton (2017) proposed for Argentina margin. However, our coincident velo ity models do not show major lateral variations: at the same depth, the Lower SDR 1 ? ve similar velocities to the Upper SDRs $(5 \mathrm{~km} / \mathrm{s}$ at $\sim 8-9 \mathrm{~km}$ depth; $6.5 \mathrm{~km} / \mathrm{s}$ at abou, 1s $\mathrm{km}$ depth). This suggests that the velocity may be controlled by depth and press' it (White et al., 1992). Alternatively, other processes related to depth may be involved, ' ucn as increasing weathering or hydrothermal alteration in the upper part, or an incre in s proportion of intrusive rocks in the lower part, but the available data do not allow to ?ecipher these hypotheses.

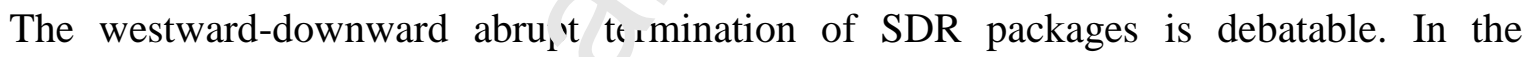
literature, these poorly underst $\mathrm{nd}$ coundaries are interpreted as landward-dipping major extensive faults (Gibson \& Lnve 1989; Eldholm et al., 1995; Geoffroy et al., 2015) or as areas flexured by dykes loading ( or sills loading (Whi、 e al. 2008). Our seismic data do not allow to resolve the debate and this is not, moreover, the $r$ urpose of this paper.

According to MCS data, the SDRs are located above Unit A (Figure 12 and Figure 13). However, the physical limit between the SDRs and Unit A is not detectable in the velocity models. This can only be explained by either no or very low acoustic impedance contrast across this transition. Unit A could be an older crust (Ante-Jurassic), composed of continental crust injected by volcanic intrusions possibly related to volcanic events responsible for the formation of the SDRs or older events related to CAMP (Bullard et al., 1965; May, 1971, Bertrand, 1991, Deckart et al., 1997, Marzoli et al., 1999, McHone, 2000; Deckart et al., 2005). It also could be part of the Guyana Shield (Costa et al., 2006). This unit could also be a neoformed crust as suggested by Gernigon et al., 2004 and Reston, 2009 in similar context 
(Vøring Basin) and could, in this case, be Jurassic in age. Our data do not allow us to distinguish clearly between these hypotheses. Nevertheless, highly probable described magma-affected middle crust or even magmatic crust such as the Namibian Margin (Bauer et al., 2000) exhibit higher velocities for similar depths (7-7.5 km/s for the Namibian margin). This result leads us to favor our first hypothesis.

A Lower unit is observed in the western part of the plateau in the MCS data sections, and is imaged in the eastern part of the plateau by the velocity models. Due to lack of continuous data at depth in the central part, and even if the Lower unit appears with comparable time thicknesses and depth, it is not possible to affirm whether they are connected and belong to the same unit. In the velocity models, the velocities of the Lower 'init range from 7.2 to 7.6 $\mathrm{km} / \mathrm{s}$, similar to previously described High Velocity Lower ${ }^{\mathrm{r}}$ 'st (HVLC) (e.g. 7.2 to 7.6 $\mathrm{km} / \mathrm{s}$ ) (Geoffroy et al. 2005). In similar contexts, surh vel scities are explained by three hypotheses: 1) an underplated unit (Planert et al., 20.1, 2) a serpentinized mantle (O'Reilly et al., 2006) or 3) a pre-rifting continental crust jutı. ded by a large amount of volcanic products as suggested by Abdelmalak et al. (20 6 f r the Voering Plateau. The serpentinized mantle is generally characterized by a : . $_{1}$. velocity layer $(7.0-7.6 \mathrm{~km} / \mathrm{s})$, difficult to distinguish in wide-angle seismic data $\mathrm{wı}^{2}{ }^{2}$ the underlying "standard" mantle (Christensen et al., 2004), making the Moho difficult in observe. In our case, we have interpreted a clearly visible PmP phase (Figure 3, Figure 7 in $i$ Figure 5). In addition, the serpentine is not stable in high temperature conditions and he presence of exhumed serpentinized mantle is restricted to depths of up to $\sim 5 \mathrm{~km}$ (e.E Laan et al., 2000). Consequently, the serpentinized mantle hypothesis is clearly not conn tible with our observations. The two remaining hypotheses both involve volcanic nrc es' es related to rifting.

In the western part of th $\sim$ plateau, the Lower unit clearly shares characteristics with the HVLC typical for volcanic margins (Geoffroy et al. 2005) in terms of shape, velocities and geometry where it is rarely described as an underplated unit. In contrast, in the eastern part of the plateau the Lower unit has a more proximal position with respect to the Jurassic margin, and exhibits a greater thickness (3-4 s TWT, corresponding to a thickness of 6-7 km according to Figure 11) reaching its maximum thickness vertically from the cretaceous eastern divergent margin slope (Figure 13) before pinching out toward the oceanic crust. This suggests that the lower unit may have distinct origin on both sides of the plateau.

We propose the westward part of the Lower unit to be related to the Jurassic rifting. As we have no velocity control, it can be either a pre-rifting continental crust intruded by a major 
amount of volcanic products Jurassic in age, or underplated magmatic material. Eastward, the lower unit may result from a distinct magmatic event, Cretaceous in age, and therefore would correspond to an underplated unit related to the cretaceous rifting event. This is in good agreement with the volcanic sills in the eastern transition domain proposed by Sapin et al. (2016) and the presence of a basaltic rocks dated to the Barremian (around $125 \mathrm{My}$ ) by well FG2-1 (Mercier et al., 2016) (Figure 10).

\subsection{Comparison of Demerara crustal velocities to different types of crust}

We compared 1D velocity-depth profiles underneath the top of the basement with those from other geological objects (Figure 14). We first co npa ed with selected TMPs from Loncke et al. (2019) and a well-documented LIP type nlaı qu near Agulhas TMP, the Agulhas Plateau (Parsiegla et al., 2008). We distinguish two ma. ${ }^{\text {n }}$ groups:

1) Demerara TMP, Agulhas TMP $\mathrm{W}$ llvis TMP, Faroe Bank, Hatton-Rockall TMP present comparable thicknesses (Fru nm et al., 2017; Parsiegla et al., 2008; Funck et al., 2008; White et al., 2009). The 'pper part of these profiles (from 0 to $6 \mathrm{~km}$ ) slightly differs, showing velocitiec $\vee{ }^{\prime} r_{j}$ ing between 4.5 to $6 \mathrm{~km} / \mathrm{s}$. However, all these geological objects show sinilar trends with depth; in particular between 6 and $22 \mathrm{~km}$ with velocities precisc!! !anging from $\sim 6.5$ to $\sim 7 \mathrm{~km} / \mathrm{s}$. These velocity values are outside of the ran o 71 unose of standard continental crust (Figure 14) as compiled by Christensen et a: $(1,95)$.

2) Falklands-Malvinas TMP (Schimschal et al., 2018; Schimschal et al., 2019) and Agulhas Plateau (Parsiegla et al., 2008) clearly differ from the first group with significantly higher velocities ranging from $\sim 6.7$ to $\sim 7.5 \mathrm{~km} / \mathrm{s}$ above the Moho and lower thicknesses. It should be noted that the Falklands-Malvinas TMP shows a very heterogeneous structure (Schimschal et al., 2018; Schimschal et al., 2019). An internal block of this TMP, the Maurice Ewing Bank, has a velocity profile similar to the Demerara Plateau. Nevertheless, the Falklands-Malvinas TMP has additional domains that differ from the structure of the Demerara Plateau. Further study is required to decide if this internal block could be an analogue for the Demerara Plateau. 
In addition, we compare our velocities to those of well-documented volcanic margins: the SE Greenland (Hopper et al., 2003) and the Namibian volcanic margins (Bauer et al., 2000). This shows that the velocities along the Greenland Margin (Hopper et al., 2003) are comparable to those of the TMPs presented in the first group (Figure 14l). This is not surprising as it is close to the Hatton-Rockall-Faroe Bank and probably undergoes a similar evolution (Hopper et al., 2003; Geoffroy et al., 2005). The velocities in the upper crust and the lower crust of the Namibian Margin (in the transitional igneous domain from Bauer et al., 2000) are similar to those observed on the Demerara Plateau (Figure 14m). The middle crust differs, with higher velocities at the Namibian Margin: over $7.0 \mathrm{~km} / \mathrm{s}$ at the top of the unit (Bauer et al., 2000) probably due to an igneous compositiı ` and large-scale intrusive magmatism (Schön et al, 1996; Bauer et al., 2000).

Figure 14: Vz comparison between Demerara Plan "1 from Figure 10) in black, Walvis

Ridge (Planert et al., 2017) in grey, Agulhas TM.' (Pa. siegla et al., 2008), Faroe Bank (Funck et al., 2008), Hatton Bank (White and S. ni.h, 2009), Rockall Bank (Vogt et al., 1998), Falklands-Malvinas Bank (Schimschal et al., . Olo, Schimschal et al., 2019), Central Agulhas Plateau (Parsiegla et al., 2008), SE Gr' enl :nd inargin (Hopper et al., 2003) and Namibian margin ( $\llcorner$ 'uer et al., 2000).

\subsection{Demerera internal geo.r el, y}

The search for analogs mist $\mathrm{k}$ ke into account the structure and subsequent possible nature of the units. Based on the $k_{\epsilon}$; dements identified for the Demerara Plateau (SDRs, Unit A, Lower unit (HVLC)), 'e : are defined two groups of possible analog structures.

The first group compused of Walvis TMP, Faroe Bank, and Hatton-Rockall TMP exhibit a three-layer organization (Figure 15 a,b,c and d). These 25-33 km thick plateaus are all located in the Atlantic. The Walvis TMP shows the closest resemblance and it is associated with a complex rifted margin offshore Namibia with a thick (about $33 \mathrm{~km}$ ) dominantly gabbroic crust according to Planert et al. (2017). Gladczenko et al. (1998) and Elliot et al. (2009) also propose a volcanic margin associated with a hotspot trail. The presence of massive SDR complex is confirmed by MCS data (Elliot et al., 2009; Jegen et al., 2016; McDermott et al., 2018). Hatton and Faroe banks also share this confirmation of a three-unit organization (even if these units are narrower), with described SDRs, HVLC and what is called a transitional or igneous crust in between, similar to Demerara Unit A. All these TMPs and margins are 
volcanic and share the characteristic of being under hotspot influence during their formation which explains the presence of SDR complex and HVLC (Fowler et al., 1989; Geoffroy et al., 2005; White et al., 2008; Elliot et al., 2008), like the Iceland hotspot for Faroe Bank and Rockall-Hatton TMPs (Elliot et al., 2008). The similarity of the structure and velocities with the Demerara TMP raises the question of the origin of the major volcanic products revealed at Demerara and suggests the possible presence of a hotspot. However, no hotspot has been clearly identified for the Demerara region in early Jurassic time even if its existence is proposed by Reuber et al. (2016) based on seismic data and Basile et al. (2020) based on deep seafloor samplings, geochemical analyses and datings.

The second group includes the Falklands-Malvinas and Amılhus plateaus (Figure 14h, i, j and k) (Figure 15e). The Falklands-Malvinas Plateau is a ht: orr,geneous plateau, composed from west to east of the Falklands-Malvinas plateau ba il. 11:-20 km overthickened oceanic domain), a possible "continental" domain (Mauricr-L v1ıg Bank) and the Georgia Basin (oceanic domain) (Schimschal et al., 2019). Exclva. $\cdot a^{\prime}$ the Maurice-Ewing Bank, which shows similar velocities to the Demerara Plateal $\left(\boldsymbol{i}_{i}\right.$ ure 14i), most of the Falklands-Malvinas TMP share similar characteristics with th $4 y$. lhas Plateau, which is defined as a LIP type "oceanic" plateau (Parsiegla et al., 2008, i this group does not show any evidence of either SDRs complexes or HVLC. These two "nlateaus" are located within the South Atlantic Ocean and their formation is also related $\mathrm{t}$ ) $\mathrm{nt}$ influence of a hotspot: the Karoo Hotspot (Linol et al., 2015; Hole et al., 2016) bu* the jo not result from the same evolution as Demerara. Consequently, not all proposed . MPs (Loncke et al., 2019) are formed by the same processes.

Notwithstanding, 5:mu ara and Walvis TMPs share similar structural characteristics with well documented muulic margins such as the Pelotas and Namibian margins (Bauer et al., 2000; Fernàndez et u.., 2010; Stica et al., 2014; Jegen et al., 2016; Planert et al., 2017). These margins (Figure 15f and $g$ ) also present a three layers type crust including: 1) an upper crust made up of SDRs, 2) a middle crust called igneous crust or transitional crust possibly a pre-SDR crust strongly intruded by volcanism with evidence of sills and dykes (Bauer et al., 2000; Fromm et al., 2017; Planert et al., 2017), and 3) a HVLC.

Based on this global analysis, we propose that the structure of the Demerara Plateau corresponds to a Jurassic volcanic margin resulting from hotspot activity. 
Jegen et al., 2016); d) Faroe Bank (White et al., 2008); e) Falklands-Malvinas TMP (Schimschal et al., 2018; 2019); f) Pelotas volcanic margin (Stica et al., 2014); g) Namibian volcanic margin (Bauer et al., 2000; Fernàndez et al., 2010).

\subsection{Origin of the volcanism of the plateau and the western margin}

Based on MCS data, Reuber et al. (2016) first hypothesized the presence of a hotspot to explain the SDRs and the subsequent huge amount of volcanic products for Demerara. This hotspot, called "Bahamas hotspot", was located close to the Bahamas at the west of the Demerara Plateau during the Jurassic period (Reuber et al., 2016). However, hotspots are active for long periods of time and their activities result in maj or volcanic expression forming hotspot tracks depending on the movement of tectonic plate, 'Murgan et al., 1983). In the case of Demerara, no such hotspot track has been documentzd

Dredges from the DRADEM experiment https://doi.ol_-'10.17600/16001900 (Basile et al., 2017) recovered various magmatic samples from he rery steep northern margin of the plateau. Some samples were precisely dated on :-" con 1'/3.4 \pm 1.6 My (Basile et al., 2017). All the magmatic samples revealed the same oatinns in trace elements, they are Light Rare Earth-enriched, and present positive anc nal es in $\mathrm{Nb}, \mathrm{Ta}, \mathrm{Zr}$ and $\mathrm{Hf}$, typical of ocean island basalts (OIB). These results indicate a possibly hotspot-related magmatic event, consistent with the opening age of the Central $x^{1}$ ?nuic and younger than the volcanism associated with CAMP (about $200 \mathrm{Ma}$ ). They sengiy support the conclusion of a major hotspot related volcanism resulting in the formatio. of the Demerara Plateau during Early/Mid Jurassic time. Basile et al. (2020) determinea ? possible hotpot track, based on the hypothesis of a hotspot located below Demerara at $170 \mathrm{Ma}$. This hotspot would also be responsible for the formation of the Sierra Leone Ris-(Basile et al., 2020). If their assumption were correct, then the Demeara Plateau would again have been located above this same hotspot in the Cretaceous.

\subsection{Evolution of the Demerara volcanic margin and the north eastern and eastern margin}

During the Cretaceous, the Demerara Plateau underwent, a second rifting phase, creating its northern (transform or highly oblique) and eastern (divergent) margins (Basile et al., 2013; Loncke et al., 2019). This specific polyphased history is at the origin of the difference between a single-phased volcanic margin and the Demerara TMP volcanic margin. 
The extent of the Jurassic volcanic margin to the east corresponds to the easternmost extension of the SDR complex, and is proposed to coincide with the actual location of the eastern edge of the plateau. Prior to the second rifting phase and following the Jurassic margin formation marked by a major Sinemurian unconformity (Mercier et al., 2016) the post-rift subsidence is compensated by the sediment supply. This subsidence accelerated in the Barremian/Aptian with the emplacement of a large delta forming the gravity-driven tectonics west to the plateau (Figure 12 and Figure 13). Later, the plateau underwent major uplift and deformation mainly during the Albian.

The narrow $(<90 \mathrm{~km}$ ) eastern margin of the plateau (Figue 13) is made of tilted blocks controlled by eastward dipping normal faults cutting in Unit $A$ anci filled by Cretaceous anteAlbian units. The first westward normal fault vertically cojnclin with the eastern edge of the plateau. Remarkably, the eastern edge also corresponds to tre easternmost extension of the SDR complex, which may then represent the extent of he Jurassic volcanic margin (Figure 12). This may reflect preferential localization of defu mation between blocks of different rheologies. This location may alternatively resu t/. $r(m$ inherited structures. In the transitional domain (Figure 13), the velocity model $d \leadsto \mathrm{n}^{+}$show evidence of an exhumed mantle dome as proposed by Sapin et al. (2016) but the egion may correspond to the top of Lower Unit 2 (around 9 s TWT in Figure 13; about $\_s$ TWT in MCS data). Therefore, in the deeper part below Unit A, Lower unit 2 reach s it maximum thickness (4 sec TD) below the eastern margin and vertically to the slow break. The unit thins eastward as do the upper and middle crust (Unit A) and rises from $25-? 2 \mathrm{~km}$ to about $13 \mathrm{~km}$ at the boundary between the transition zone and the oceanic domain.

The northeastern $\mathrm{m}_{\mathrm{\iota}}$ "gin appears wider $(120 \mathrm{~km})$ but is cut obliquely by the seismic section. It looks more 11 ke a horst and graben type structure controlled by normal faults dipping alternatively toward the northeast or the south-west and filled by possibly Cretaceous ante-Albian deposits (Figure 12). It appears that northeastern extent of the SDRs also coincides with the internal limit of the margin. Nevertheless, continuity toward the north of the SDRs volcanic complex has been proved at the Guinean Plateau (Mercier de Lépinay, 2016) which was north of Demerara before Cretaceous rifting (Moulin et al., 2010). At depth, below Unit A, Lower unit 2 also appears distinct with a globally lower thickness (2-3 sec TWT) and its depth remains stable around 27-32 km (Figure 12). It ends up before a rapid rise of the Moho (30 to $20 \mathrm{~km}$ ) within the middle crust (Unit A). 
Subsequently, interpretation of northeastern and eastern margins is not comparable. The specific structure of the northeastern margin may be related to its position at the outer corner corresponding to the intersection between the transform and divergent segments (Mercier et al, 2016). The eastern margin is a more "standard" narrow divergent margin as imaged by Sapin et al. (2016). Lower unit 2 (see $\S$ IV. A.) may result from a second (rifting related) cretaceous volcanic event and correspond to an underplated unit due to the hypothetic hotspot come back as suggested by Basile et al. (2020).

\section{Conclusions}

The interpretation of unpublished seismic data (id -angle and reflection seismic data) reveals the deep structure of the Demerara Plate $九$. This paper provides new information on the geometry of the layers and their physical proprties. We imaged a crustal domain composed of a three-layer crust: as already obs $e_{v \in \mathcal{A}} \mathrm{by}$ Reuber et al. (2016), the first layer (from the top) is a large SDR complex, $w^{\prime} \cdot h$ : subdivided into four major units. Our result demonstrates that this SDR complex is, resent from the west of the plateau (maximum thickness) to the east. Below this unit, ve observed another layer (Unit A) thanks to a clear acoustic facies difference. This sec 1 , art may correspond to an ante-SDR crust reworked by the volcanic episode. SDR c.mpıex and Unit A present high velocities from 4.5 to 6.5 $\mathrm{km} / \mathrm{s}$, higher than "standard" cuntinental crust (Christensen and Mooney; 1995) at similar depths. One important result is that the boundary between SDRs and Unit A, identifiable in MCS, is not clearly hs $\cdot{ }^{-r v}$ : ole in velocity models. This probably reveals similar physical parameters (density, acov tic impedance). The deeper crustal part is composed of two lower units: Lower Unit 1 is imaged by MCS in the west of the plateau and Lower Unit 2 is imaged by WAS (wide-angle seismic) data in the east. These units could be a high velocity lower crust (HVLC), since Lower Unit 2 presents velocities from 7.2 to $7.6 \mathrm{~km} / \mathrm{s}$. As afore mentioned, seismic velocities in the crustal domain differ from those of "standard" continental margins but they are similar to those of other TMPs and volcanic margins.

The fan shaped massive SDR units and their internal reflectors are dip toward the west indicating the presence of a volcanic rift axis westward during an intense Jurassic volcanic episode. Consequently, the Demerara Plateau exhibits all aspects of a volcanic margin toward the western Central Atlantic segment. Additional comparisons show similarities with other 
TMPs in the Atlantic. However, not all TMPs correspond to these characteristics, with exceptions such as the Falklands-Malvinas and Agulhas TMP. In contrast, the comparison of Demerara with the Namibian or Pelotas volcanic margin reveals once again a very similar organization a 3-layers crust, with an upper SDRs crust and a HVLC. All of them show relatively comparable velocities. These similarities emphasize the possibility of a hotspot related formation for the Jurassic Demerara Margin.

Even though not all TMPs are imaged by such complete seismic data sets as Demerara, some of them share similar characteristics, at least to first order. The major result for Demerara is that this plateau corresponds to a large Jurassiz volcanic margin reworked in its eastern part by a second rifting event: the Cretaceous trap $f^{\prime} r_{1}$-dominated rifting. Many questions remain concerning the northern margin: the nori... ard continuity of the SDR complex, notably beyond the conjugate of the northern 1 la $a_{2}$ ri*, which is the southern limit of the Guinea Plateau. The influence of the establishme nt if a Cretaceous transform margin on the structure of the Jurassic volcanic margin requires fun her investigation. The exploitation of supplementary data related to the northern trat $s^{f}$ or $n$ border is imperative. This will be the next step of this project. Moreover, futr a stu dies of the structure and nature of different TMPs are requisite in order to define comı 'on processes, involving major thermal anomalies such as hotspots and superposed tectonı phases

\section{Acknowledgments}

We would like to that.' $h_{1}$ : captain and the crew of R/V L'Atalante as well as the technical team of Genavir and If - ner for their help in data acquisition during the MARGATS cruise. We also acknowledge Région Bretagne and Ifremer for funding the $\mathrm{PhD}$ scholarship associated with this work. TOTAL is acknowledged for providing access to their marine seismic dataset from the Demerara region. The GMT software package (Wessel and Smith, 1995) was used in the preparation of this paper for several figures), and the SU (Seismic Unix) software was used for processing the WAS data as well as for the calculation of synthetic data (Cohen \& Stockwell, 2003). We would like to thank Wilfried Jokat, Associate Editor and an anonymous rewiever for their constructive reviews, which greatly helped improve the manuscript. We would like to warmly thank native speaker Alison Chalm for the English correction of the manuscript. 
Credit Author Statement

Please find below the individual contributions of all the authors of this paper.

Thomas Museur: Conceptualization, Methodology, Formal analysis, Formal analysis, Investigation, Data curation, Writing.

David Graindorge: Conceptualization, Writing - Review \& Editing, Supervision, Funding acquisition.

Frauke Klingelhoefer: Conceptualization, Methodology, Software, Validation, Supervision, Writing - Review \& Editing, Funding acquisition.

Walter R. Roest: Conceptualization, Writing - Review \& Editing, Supervision, Funding acquisition.

Christophe Basile: Writing - Review \& Editing.

Lies Loncke: Writing - Review \& Editing.

François Sapin: Writing - Review \& Editing.

\section{Declaration of interests}

$\bigotimes$ The authors declare that they have no known c imp ting financial interests or personal relationships that could have appeared to influence th $2 \mathrm{~h}$ rok reported in this paper.

\section{References}

Auffret, Y., Pelleau, P., Klingelhoefer, $\ulcorner$ Geli, L., Crozon, J., Lin, J.Y., Sibuet, J.-C. (2004), MicrOBS : A new generation of ocf an bottom seismometer. First break volume, technical article.

Abdelmalak, M. M., Planke, s Faleide, J. I., Jerram, D. A., Zastrozhnov, D., Eide, S., \& Myklebust, R. (2016). Trec c'velopment of volcanic sequences at rifted margins: New insights from the structure ana morphology of the Vøring Escarpment, mid-Norwegian Margin. Journal of Geophysical Kesearch: Solid Earth, 121(7), 5212-5236.

Amante, C. and B.W. Eakins, (2009). ETOPO1 1 Arc-Minute Global Relief Model: Procedures, Data Sources and Analysis. NOAA Technical Memorandum NESDIS NGDC-24. National Geophysical Data Center, NOAA. doi:10.7289/V5C8276M.

Barker, P.. (1999). Evidence for a volcanic rifted margin and oceanic crustal structure for the Falkland Plateau Basin. Journal of The Geological Society - J GEOL SOC. 156. 889-900. 10.1144/gsjgs.156.5.0889.

Basile, C., Maillard, A., Patriat, M., Gaullier, V., Loncke, L., Roest, W., Mercier de Lépinay, M. \& Pattier, F. (2013), Structure and evolution of the Demerara Plateau, offshore French 
Guiana: Rifting, tectonic inversion and post-rift tilting at transform-divergent margins intersection, Tectonophysics 591, 16-29.

Basile, C., Girault, I., Heuret, A., Loncke, L., Poetisi, E., Graindorge, D., \& Roest, W. (2017). Morphology and lithology of the continental slope north of the Demerara marginal plateau: results from the DRADEM cruise. EGUGA, 8107.

Basile, C., Girault, I., Paquette, J. L., Agranier, A., Loncke, L., Heuret, A., \& Poetisi, E. (2020). The Jurassic magmatism of the Demerara Plateau (offshore French Guiana) as a remnant of the Sierra Leone hotspot during the Atlantic rifting. Scientific Reports, 10(1), 112.

Bauer, Klaus \& Neben, Sönke \& Schreckenberger, Bernd \& Fmnırmann, Rolf \& Hinz, Karl \& Fechner, Notker \& Gohl, Karsten \& Schulze, Albrecht \& Tr.mbull, R. \& Weber, Klaus. (2000). Deep structure of the Namibia continental $n_{\imath}$ roi $_{1}$ as derived from integrated geophysical studies. Journal of Geophysic ^ Research. 105. 25829-25854. $10.1029 / 2000 J B 900227$.

Bertrand, H., Villeneuve, M., (1989). Témoin ' C' l' Juverture de l'atlantique central au début du jurassique: les dolérites tholéiitiques jor tint.itales de Guinée (Afrique de l'Ouest). C.R. Acad. Sci., Paris 308 (série II), 93-98.

Biari, Y., Klingelhoefer, F., Sahabi, iv sslanian, D., Schnurle, P., Berglar, K., Moulin, M., Mehdi, K., Graindorge, D., Evi.in, Li., Benabdellouahed, M., Reichert, C., (2015). Deep crustal structure of the North- ${ }^{\mathbf{v}} /$ est African margin from combined wide-angle and reflection seismic data (MIRROR seismic survey). Tectonophysics 656, 154174.doi:10.1016/j.tecto.2 J1د 96.019

Blaich, O. A., Faleide, J. ., Tsikalas, F., Gordon, A. C. \& Mohriak, W. (2013). Crustal-scale architecture and segmentation of the South Atlantic volcanic margin. Geol. Soc., London, Sp. Pub. 369, 167-183.

Bonvalot, S., Balmino, G., Briais, A., M. Kuhn, Peyrefitte, A., Vales N., Biancale, R., Gabalda, G., Reinquin, F., Sarrailh, M., (2012). World Gravity Map. Commission for the Geological Map of the World. Eds. BGI-CGMW-CNES-IRD, Paris.

Bullard, E., Everett, J.E., Smith, A.G., (1965). The fit of the continents around the Atlantic. In: Bickett, P.M.S., Bullard, E., Runcorn, S.K. (Eds.), A Symposium on Continental Drift, Philos. Trans. R. Soc. Lond., A, vol. 258, pp. 41- 51. 
Campan, A., (1995). Analyse cinématique de l'Atlantique Equatorial, implications sur l'évolution de l'Atlantique Sud et sur la frontière de plaque Amérique du Nord / Amérique du Sud, PhD Thesis, Univ. "Pierre et Marie Curie", Paris VI, 352 pp.

Cohen, J. K., \& Stockwell, J. W. Jr. (2003). CWP/SU: Seismic Unix release no. 36: A free package for seismic research and processing. Center for Wave Phenomena, Colorado School of Mines.

Cohen, J. K., \& Stockwell, J. W. (2003). Seismic Unix Release 37: a freed package for seismic research and processing. Center for Wave Phenomena, Colorado School of Mines.

Christensen, N. I., and W. D. Mooney (1995), Seismic velocity structure and composition of the continental crust: A global view, J. Geophys. Rt s., 100(B6), 9761-9788, doi:10.1029/95JB00259.

Christensen, N., (2004). Serpentinites, Peridotites, _. J zismology. International Geology Review - INT GEOL REV. 46. 795-816. 10.2747/002، ‘ ‘ 14.46.9.795.

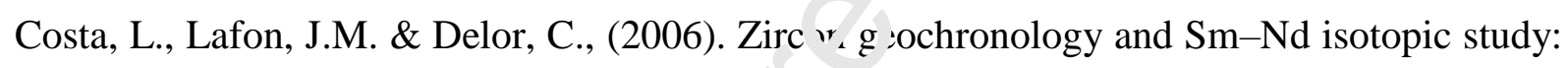
Further constraints for the Archean an $r$. I ale nroterozoic geodynamical evolution of the southeastern Guiana Shield, north of A.'’zonian Craton, Brazil. Gondwana Research GONDWANA RES. 10. 277-300. 10.1 ‘6/j.gr.2006.02.012.

Deckart, K., Féraud, G., Bertrand Y., (1997). Age of Jurassic continental tholeiites of French Guyana, Surinam and Guinea. in ${ }_{1}$ lications for the initial opening of the Central Atlantic Ocean. Earth Planet. Sci. Lett. : 50, 205-220.

Deckart, Katja \& Bertrı nd, Hervé \& Liégeois, J.-P. (2005). Geochemistry and Sr, Nd, Pb isotopic composition of he Central Atlantic Magmatic Province (CAMP) in Guyana and Guinea. Lithos. 82. 282-314. 10.1016/j.lithos.2004.09.023.

Delong, D., (2018). Wide-angle seismic survey of the East-Sicily margin: Crustal structure of the lonian basin and Malta escarpement and implications for the current STEP fault location.

Elliott, Gavin \& Berndt, Christian \& Parson, Lindsay. (2009). The SW African volcanic rifted margin and the initiation of the Walvis Ridge, South Atlantic. Marine Geophysical Researches. 30. 207-214. 10.1007/s11001-009-9077-x.

Fanget, A.N., Loncke, L., Pattier, F., Marsset, T., Roest, W., Tallobre, C., Durrieu de Madron, X., Hernández-Molina, F., (2019). A synthesis of the sedimentary evolution of the Demerara 
Plateau (Central Atlantic Ocean) from the late Albian to the Holocene. Marine and Petroleum Geology. 104195. 10.1016/j.marpetgeo.2019.104195.

Fernàndez, M., Afonso, J., Ranalli, G., (2010). The deep lithospheric structure of the Namibian volcanic margin. Tectonophysics. 481. 10.1016/j.tecto.2009.02.036.

Fromm, T., Jokat, W., Ryberg, T., Behrmann, J., Haberland, C., Weber, M., (2017). The onset of Walvis Ridge: Plume influence at the continental margin. Tectonophysics. 716. 90-107. 10.1016/j.tecto.2017.03.011.

Funck, T., Morten Sparre, A., Neish, J., Dahl-Jensen, T., (2008). A refraction seismic transect from the Faroe Islands to the Hatton-Rockall Basin. Journal (. Geophysical Research. 113. 10.1029/2008JB005675.

Gerlings, J., Funck, T., Jackson, H. R., Louden, K. E. ^1 1 K ingelhöfer, F. (2009), Seismic evidence for plume-derived volcanism during formati . $_{\text {. }}$ the continental margin in southern Davis Strait and northern Labrador Sea. Geophysicai 'ournal International, 176: 980-994. doi:10.1111/j.1365-246X.2008.04021.x

Geoffroy, L. (2005). Volcanic passive m־y. ns. Tomptes Rendus Geoscience, 337(16), 1395 1408 .

Geoffroy, L., Burov, E. B., \& Wern :.: ト. (2015). Volcanic passive margins: another way to break up continents. Scientific rer $=$ rts, $5(1), 1-12$.Gladczenko, T. P., Skogseid, J., \& Eldhom, O. (1998). Namibia volcanic m. rg $_{\Perp}$ `Marine Geophysical Researches, 20(4), 313-341.

Gouyet, S. (1988), Évoluti`n te -iono-sédimentaire des marges guyanaise et nord-brésilienne au cours de l'évolution d l'A lantique Sud, Université de Pau et des pays de l'Adour, 374pp.

Graindorge, D., A. Cala ıorrano, P. Charvis, J.-Y. Collot, and N. Bethoux (2004), Deep structures of the Ecuador convergent margin and the Carnegie Ridge, possible consequence on great earthquakes recurrence interval, Geophys. Res. Lett., 31, L04603, doi:10.1029/2003GL018803.

Greenroyd, C. J., Peirce, C., Rodger, M., Watts, A. B., \& Hobbs, R. W. (2007). Crustal structure of the French Guiana margin, west equatorial Atlantic. Geophysical Journal International, 169(3), 964-987.

Greenroyd, C. J., Peirce, C., Rodger, M., Watts, A. B., \& Hobbs, R. W. (2008). Demerara Plateau-The structure and evolution of a transform passive margin. Geophysical Journal International, 172(2), 549-564. https://doi.org/10.1111/j.1365-246X.2007.03662.x 
Hole, Malcolm \& Ellam, Rob \& Macdonald, David \& Kelley, Simon. (2015). Gondwana break-up related magmatism in the Falkland Islands. Journal of the Geological Society. 10.1144/jgs2015-027.

Jegen, M., Avdeeva, A., Berndt, C., Franz, G., Heincke, B., Hölz, S., Kopp, H. (2016). 3-D magnetotelluric image of offshore magmatism at the Walvis Ridge and rift basin. Tectonophysics, 683, 98-108.

Jourdan, F., Marzoli, A., Bertrand, H., Cirilli, S., Tanner, L. H., Kontak, D. J., Bellieni, G. (2009). 40Ar/39Ar ages of CAMP in North America: implications for the Triassic-Jurassic boundary and the $40 \mathrm{~K}$ decay constant bias. Lithos, 110(1-4), 1( 7-180.

Klitgord, K. D., \& Schouten, H. (1986). The western north Atli ntic region. The Decade of North American Geology, 1000, 351-378.

Koopmann, H., (2013). Segmentation and volcano satu nic characteristics along the SW African continental margin, South Atlantic, as dei. ed from multichannel seismic and potential field data. Marine and Petroleum Geolr gr 50, 22-39.

Labails, C., Olivet, J.L., Aslanian, D. and n res, W. R., (2010). An alternative early opening scenario for the Central Atlantic Ocean. L'rth and Planetary Science Letters 297, 355-368. doi: 10.1016/j.eps1.2010.06.024.Ludw1s, W.J.,

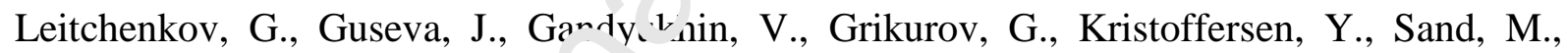
Aleshkova, N. (2008). Crustal stru ture and tectonic provinces of the Riiser-Larsen Sea area (East Antarctica): results of ge ᄁhysical studies. Marine Geophysical Researches, 29(2), 135158.

Linol, B., de Wit, M. ․, Guillocheau, F., Robin, C., Dauteuil, O. (2015). Multiphase Phanerozoic subsidence and uplift history recorded in the Congo Basin: a complex successor basin. In Geology and Resource Potential of the Congo Basin (pp. 213-227). Springer, Berlin, Heidelberg.

Loncke, L., Droz, L., Gaullier, V., Basile, C., Patriat, M., \& Roest, W. (2009). Slope instabilities from echo-character mapping along the French Guiana transform margin and Demerara abyssal plain. Marine and Petroleum Geology, 26(5), 711-723.

Loncke, L., Maillard, A., Basile, C., Roest, W. R., Bayon, G., Gaullier, V., Marsset, T. (2016). Structure of the Demerara passive-transform margin and associated sedimentary 
processes. Initial results from the IGUANES cruise. Geological Society, London, Special Publications, 431(1), 179-197.

Loncke, L., Roest, W. R., Klingelhoefer, F., Basile, C., Graindorge, D., Heuret, A., Marcaillou, B., Museur, T., Fanget, A. S., \& Mercier de Lépinay, M. (2019). Transform marginal plateaus. AGUFM, 2019, T32B-06.

Loureiro, A., Afilhado, A., Matias, L., Moulin, M., \& Aslanian, D. (2016). Monte Carlo approach to assess the uncertainty of wide-angle layered models: Application to the Santos Basin, Brazil. Tectonophysics, 683, 286-307. https://doi.org/10.1016/j.tecto.2016.05.040

Ludwig, W. J., Nafe, J. E., \& Drake, C. L. (1970). Seismic refı -tion. The sea, 4(part 1), 5384.

Marzoli, A., Renne, P.R., Piccirillo, E.M., Ernesto, M. ' 'eM in, A., (1999). Extensive 200-

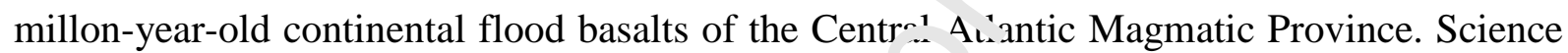
$284,616-618$.

Matthews, K. J., Maloney, K. T., Zahirovic, S., V.il iams, S. E., Seton, M., \& Mueller, R. D. (2016). Global plate boundary evolution sti' kn' ${ }^{\prime}$ matics since the late Paleozoic. Global and Planetary Change, 146, 226-250.

May, P.R., (1971). Patterns of Triass:- diubase dikes around the North Atlantic in the context of predrift position of the continer (' Jl. Soc. Amer. Bull. 82, 1285-1292.

McDermott, C., Lonergan, L., Cohier, J. S., McDermott, K. G., \& Bellingham, P. (2018). Characterization of Seawar ${ }^{2}-\mathrm{D} 1$, ping Reflectors Along the South American Atlantic Margin and Implications for Cor ine tal Breakup. Tectonics, 37(9), 3303-3327.

McHone, G.J., (2000). N'n-plume magmatism and rifting during the opening of the Central Atlantic Ocean. Tectonophysics 316, 287- 296.

Menzies, M. A. (Ed.). (2002). Volcanic rifted margins (Vol. 362). Geological Society of America.

Mercier de Lépinay, M., Loncke, L., Basile, C., Roest, W. R., Patriat, M., Maillard, A., \& De Clarens, P. (2016). Transform continental margins-Part 2: A worldwide review. Tectonophysics, 693, 96-115. https://doi.org/10.1016/j.tecto.2016.05.038

Mjelde, P., Digranes, H., Shimamura, H., Shiobara, S., Kodaira, H., Brekke, T., Egebjerg, N., Sørenes, S. and Thorbjørnsen, C., (1998). Crustal structure of the northern part of the Vøring 
Basin, mid-Norway margin, from wide- angle seismic and gravity data, Tectonophysics, Volume 293, Issues 3-4, 15 August 1998, Pages 175-205, ISSN 0040-1951, http://doi.org/10.1016/S0040 1951(98)00090-0.

Moulin, M., Aslanian, D. \& Unternehr, P. (2010), A new starting point for the South and Equatorial Atlantic Ocean, Earth-Science Reviews 98(1-2), 1-37.

Nafe, J.E., and Drake, C.L., (1970), Seismic refraction, in The Sea, A.E. Maxwell (Editor), Vol. 4, Wiley-Interscience, New York, pp. 53-84.

Okay, Nilgun. (1995). Thermal development and rejuvenation of the marginal plateaus along the transtensional volcanic margins of the Norwegian-Greenlani Sea /.

Operto, S. Q Charvis, P., (1995). Kerguelen Plateau: a vol эni, passive margin fragment? Geology, 23, 137-140.

O'Reilly, B. \& Hauser, F. \& Ravaut, C. \& Shann on, P. \& Readman, P. (2006). Crustal thinning, mantle exhumation and serpentinization i the Porcupine Basin, offshore Ireland: Evidence from wide-angle seismic data. Journa' of The Geological Society - J GEOL SOC. 163. 775-787. 10.1144/0016-76492005-0^.

Pattier, F., Loncke, L., Gaullier, V. Basilt, C., Maillard, A., Imbert, P. and Loubrieu, B. (2013). Mass-transport deposits and sllli venting in a transform margin setting, the eastern Demerara Plateau (French Guiana), M…ne and Petroleum Geology, 46, 287-303.

Pattier, F., Loncke, L., Imber, P., Gaullier, V., Basile, C., Maillard, A., Bayon, G. (2015). Origin of an enigmatic regi ${ }^{\prime}$ nal Mio-Pliocene unconformity on the Demerara plateau. Marine Geology, 365, 21-35.

Paton, D., \& Pindell, I. McDermott, K., Bellingham, P., Horn, B. (2017). Evolution of seaward-dipping reflectors at the onset of oceanic crust formation at volcanic passive margins: Insights from the South Atlantic. Geology. 45. 10.1130/G38706.1.

Parkin, C. \& White, R.. (2008). Influence of the Iceland mantle plume on oceanic crust generation in the North Atlantic. Geophysical Journal International. 173. 168 - 188. 10.1111/j.1365-246X.2007.03689.x.

Parsiegla, N., Gohl, K., Uenzelmann-Neben, G. (2007). Deep crustal structure of the sheared South African continental margin: first results of the Agulhas-Karoo Geoscience Transect. South African Journal of Geology, 110(2-3), 393-406. 
Planert, L., Behrmann, J., Jokat, W., Fromm, T., Ryberg, T., Weber, M., Haberland, C. (2017). The wide-angle seismic image of a complex rifted margin, offshore North Namibia: implications for the tectonics of continental breakup. Tectonophysics, 716, 130-148.

Reuber K., Pindell J., Horn B. (2016). ”Demerara Rise, offshore Suriname: Magma-rich segment of the Central Atlantic Ocean, and conjugate to the Bahamas hot spot." Interpretation, 4(2), T141-T155. doi: 10.1190/INT-2014-0246.1

Smith, W. H., \& Sandwell, D. T. (1997). Global sea floor topography from satellite altimetry and ship depth soundings. Science, 277(5334), 1956-1962.

Sapin, F., Davaux, M., Dall'Asta, M., Lahmi, M., Baudot, G., \& Ringenbach, J. C. (2016). Post-rift subsidence of the French Guiana hyper-obliq e 1 largin: from rift-inherited subsidence to Amazon deposition effect. Geological Soc ety, London, Special Publications, 431(1), 125-144.

Sandwell, D. T., R. D. Müller, W. H. F. Smith, E. Ga cia, R. Francis, (2014).New global marine gravity model from CryoSat-2 and Jasor. 1 reveals buried tectonic structure, Science, Vol. 346, no. 6205, pp. 65-67, doi: 10.1126/sr telu-1258213.

Schimschal, C., \& Jokat, W., (2018). T'e c.ustal structure of the continental margin east of the Falkland Islands. Tectonophysics. 724-7'̌․ 234-253. 10.1016/j.tecto.2017.11.034.

Schimschal, C. M., \& Jokat, W. (2 )1y, The crustal structure of the Maurice Ewing Bank. Tectonophysics, 769, 228190.

Schön, J. H., (1996) Phys: aı Properties of Rocks: Fundamentals and Principles of

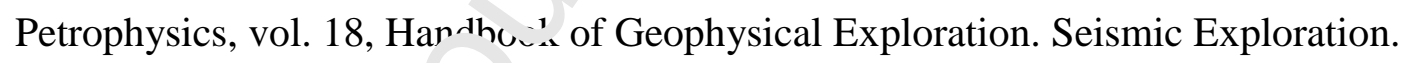

Stica, J. M., Zalán, P. ' \& Ferrari, A. L., (2014). The evolution of rifting on the volcanic margin of the Pelotas Dasin and the contextualization of the Paraná-Etendeka LIP in the separation of Gondwana in the South Atlantic. Marine and Petroleum Geology 50, 1-21

Stockwell, D. (1999). The GARP modelling system: problems and solutions to automated spatial prediction. International journal of geographical information science, 13(2), 143-158.

Tallobre, C., Loncke, L., Bassetti, M. A., Giresse, P., Bayon, G., Buscail, R., Sotin, C. (2016). Description of a contourite depositional system on the Demerara Plateau: Results from geophysical data and sediment cores. Marine Geology, 378, 56-73.

Vogt, U., Makris, J., O'Reilly, B. M., Hauser, F., Readman, P. W., Jacob, A. B., \& Shannon, P. M. (1998). The Hatton Basin and continental margin: Crustal structure from wide-angle 
seismic and gravity data. Journal of Geophysical Research: Solid Earth, 103(B6), 1254512566.

Welford, J. K., Shannon, P. M., O’Reilly, B. M., \& Hall, J. (2012). Comparison of lithosphere structure across the Orphan Basin-Flemish Cap and Irish Atlantic conjugate continental margins from constrained 3D gravity inversions. Journal of the Geological Society, 169(4), 405-420.

White, R. S., Westbrook, G. K., Fowler, S. R., Spence, G. D., Barton, P. J., Joppen, M., Bott, M. H. P. (1987). Hatton Bank (northwest UK) continental margin structure. Geophysical Journal International, 89(1), 265-272.

White, R. S., D. McKenzie, and R. K. O'Nions (1992), Ocean c c1 istal thickness from seismic measurements and rare earth element inversions, J. Geol hys Res., 97(B13), 19683-19715, doi:10.1029/92JB01749.

White, R. S., Smith, L. K., Roberts, A. W., Christie, F. ^. F., \& Kusznir, N. J. (2008). Lowercrustal intrusion on the North Atlantic continent $1^{\text {r }} \mathbf{1}^{\urcorner}$rgin. Nature, 452(7186), 460.

White, R. S., \& Smith, L. K. (2009). Cr ss 1 s. ucture of the Hatton and the conjugate east Greenland rifted volcanic continental marg. 's, NE Atlantic. Journal of Geophysical Research: Solid Earth, 114(B2).

Zelt, C. A., \& Smith, R. B. (190?). C ismic travel-time inversion for 2-D crustal velocity structure. Geophysical Journal inte. national, 108(16-34), 1992.

Zelt, C. A. (1999). Modelling st ategies and model assessment for wide-angle seismic traveltime data. Geophysical J urn ll International, 139(1), 183-204. https://doi.org/10.1046/j.1365246X.1999.00934.X

\begin{tabular}{|c|c|c|c|}
\hline MAR01 profile & Nb picks & Trms & Chi $^{2}$ \\
\hline Wat & 3729 & 0,066 & 4,896 \\
Sed 1 & 939 & 0,099 & 2,727 \\
Sed 2 & 426 & 0,09 & 2,274 \\
Sed refl 1 & 764 & 0,052 & 0,755 \\
Sed refl 2 & 698 & 0,059 & 0,968 \\
Uc & 2538 & 0,088 & 0,952 \\
Up crust refl & 205 & 0,104 & 1,341 \\
Mc & 11205 & 0,154 & 2,914 \\
Pn & 2483 & 0,204 & 2,882 \\
PmP & 747 & 0,121 & 1,011
\end{tabular}




\begin{tabular}{|c|c|c|c|}
\hline Lc refl & 340 & 0,368 & 9,411 \\
\hline MAR02 profile & Nb picks & Trms & Chi $^{2}$ \\
\hline Wat & 2379 & 0,017 & 0,029 \\
Sed 1 & 374 & 0,083 & 0,684 \\
Sed 2 & 420 & 0,06 & 0,366 \\
Sed refl 1 & 602 & 0,04 & 0,158 \\
Uc & 2479 & 0,106 & 1,13 \\
Mc & 5355 & 0,137 & 1,875 \\
Lc & 2210 & 0,263 & 6,904 \\
Pn & 199 & 0,183 & 3,369 \\
PmP & 200 & 0,35 & 9,258 \\
\hline
\end{tabular}

Table 1: Summary Table of the main uncertainties for MAR01 and M $\cong$ Ri2 Velocity Models. 


\section{Legend}

Bathymetry (m)

$-4000$

$-3500$

$-3000$

$-2500$

$-2000$

$-1500$

$-1000$

$-500$

$\square 0$

Altitude (m)

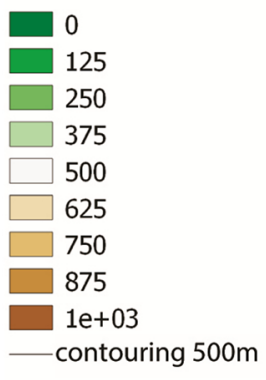

OBS and MCS

Only MCS

SLEA

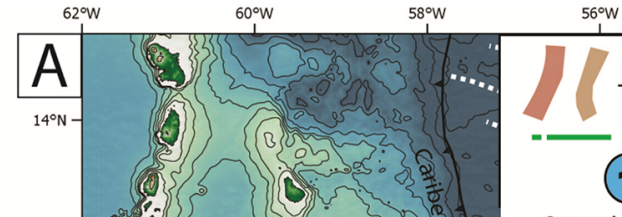

$6^{50} \mathrm{~W}$

$54^{\circ} \mathrm{W}$

$52^{\circ} \mathrm{W}$

$50^{\circ} \mathrm{W}$

$48^{\circ} \mathrm{W}$

$46^{\circ} \mathrm{W}$

Jura. and Cret. Divergent margins

Transform or oblique margin

(1)

(2)

Central Atlantic Equatorial Atlantic

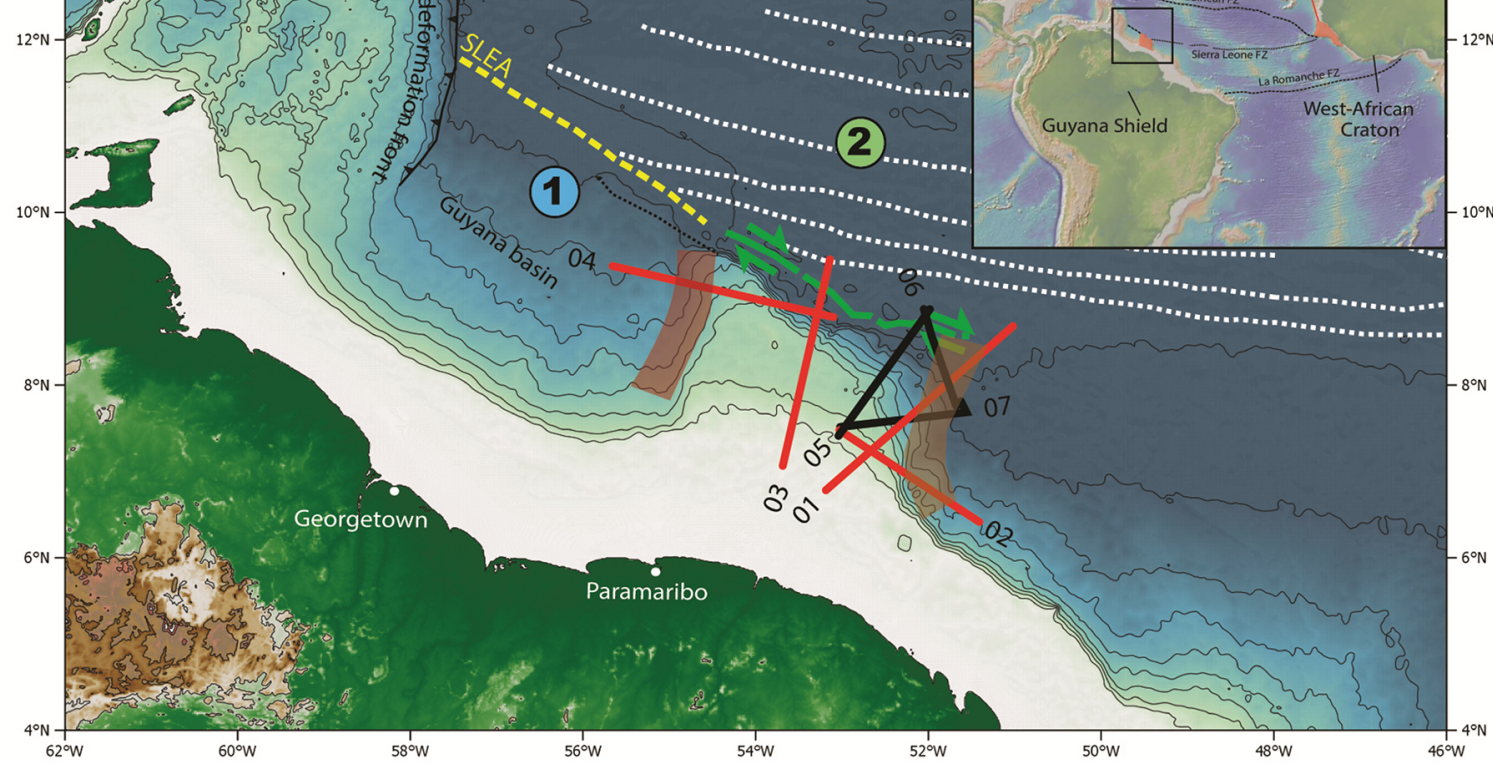

Figure 1 
a) Present day

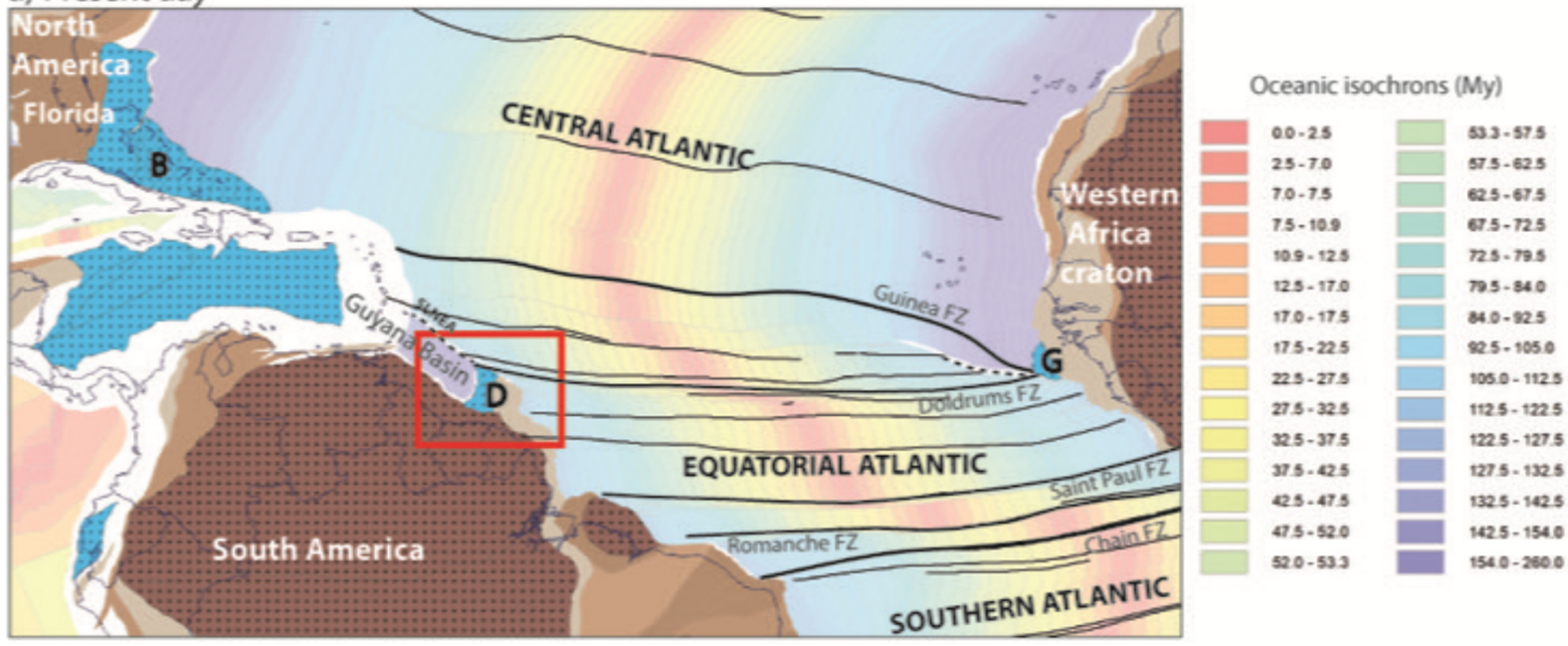

b) Position at $80 \mathrm{My}$

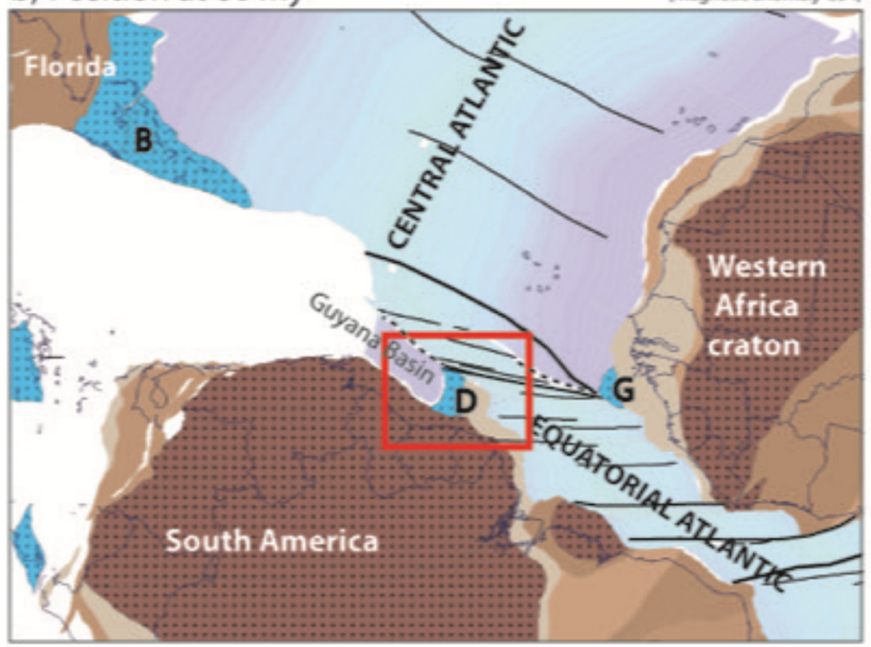

c) Position at 120 My (Best-Fit Equatorial Atlantic)

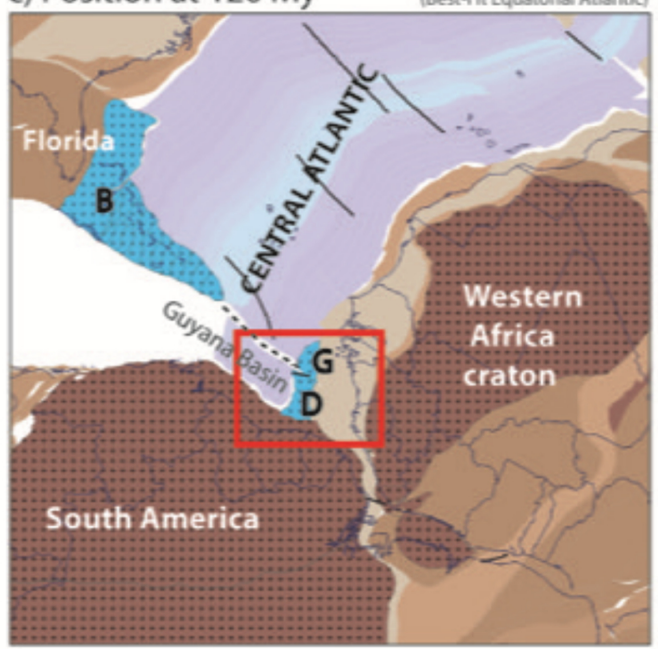

d) Position at $160 \mathrm{My}$ magnetic anomaly)

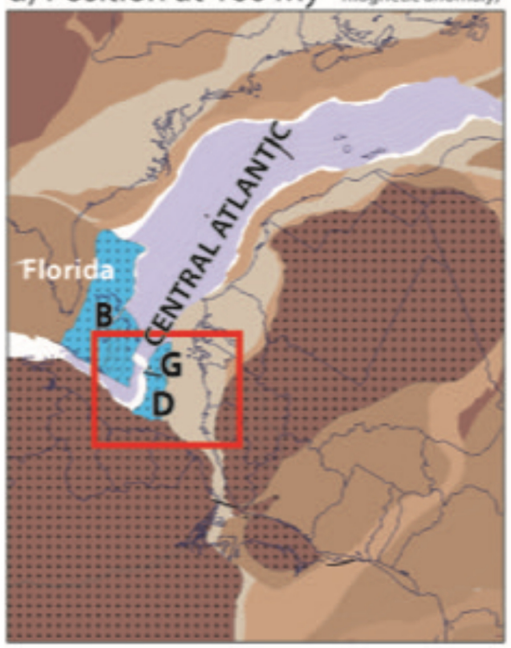

e) Position at $200 \mathrm{My}$ Central Atlantic

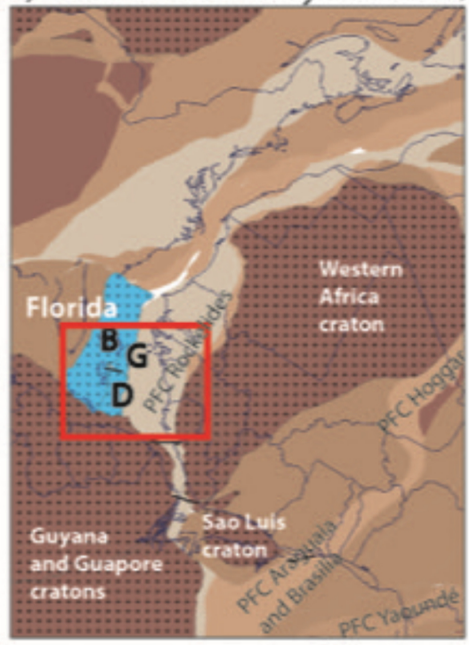

Key geologic elements

+++ Cratons

v v Magmatic plateaus

Continental terranes ages

Mésozoïc and Cenozoïc basins

Paleozoïc terranes

Neoproterozoïc terranes

Mesoproterozoïc terranes

Paleoproterozoïc terranes

Archean terranes 
MARGATS MAR01, OBS 13
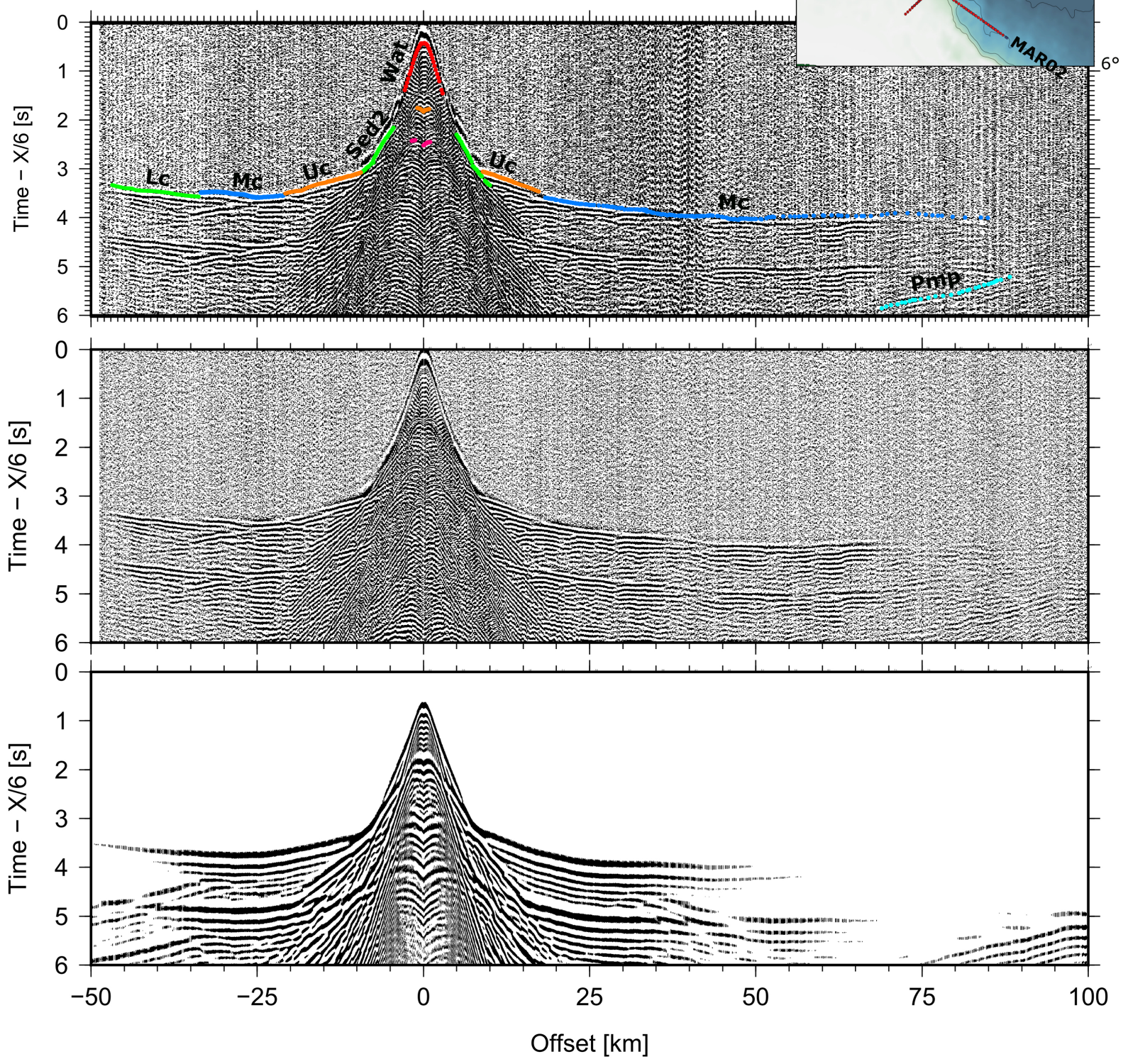

Figure 3 

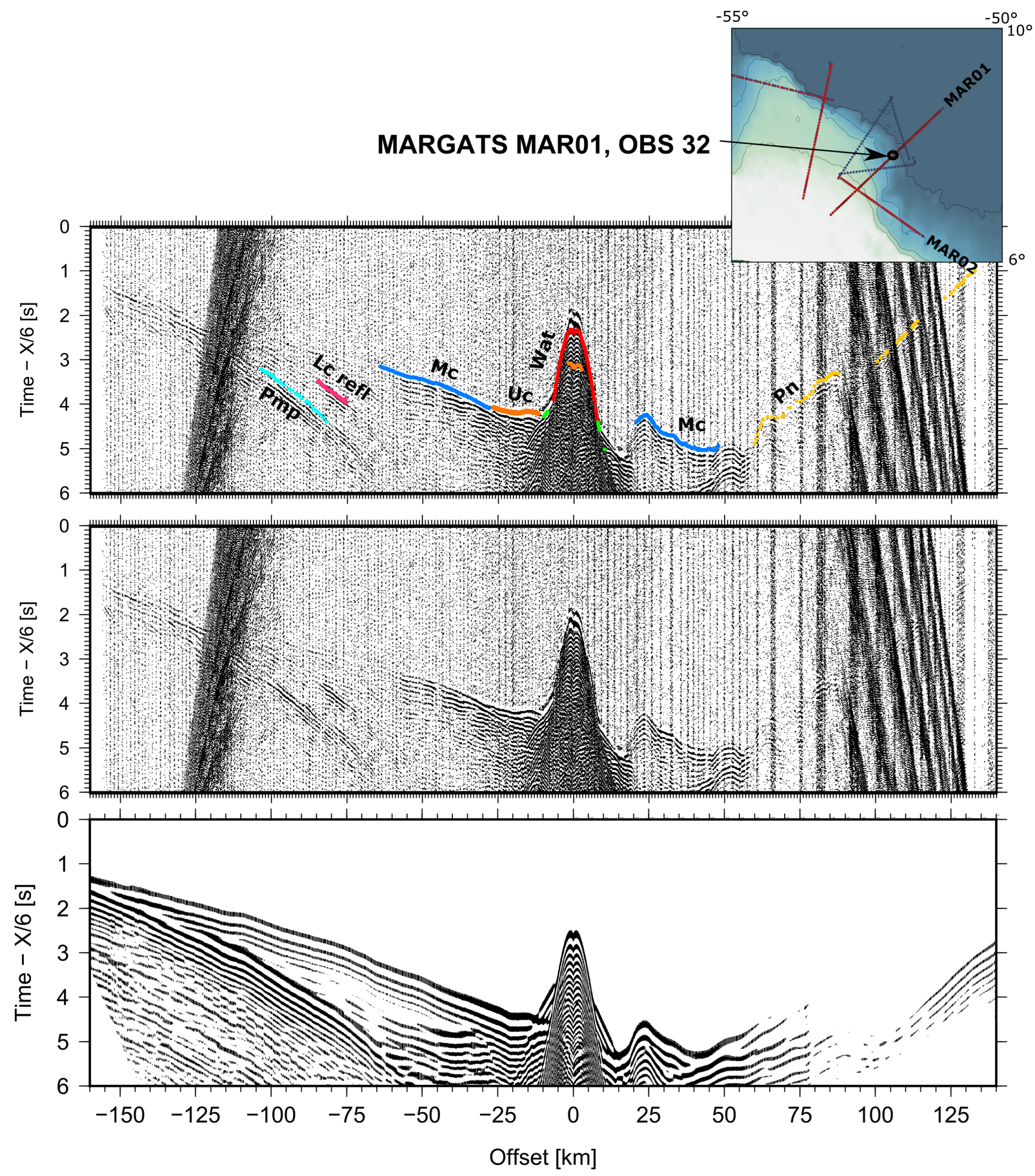

Figure 4 


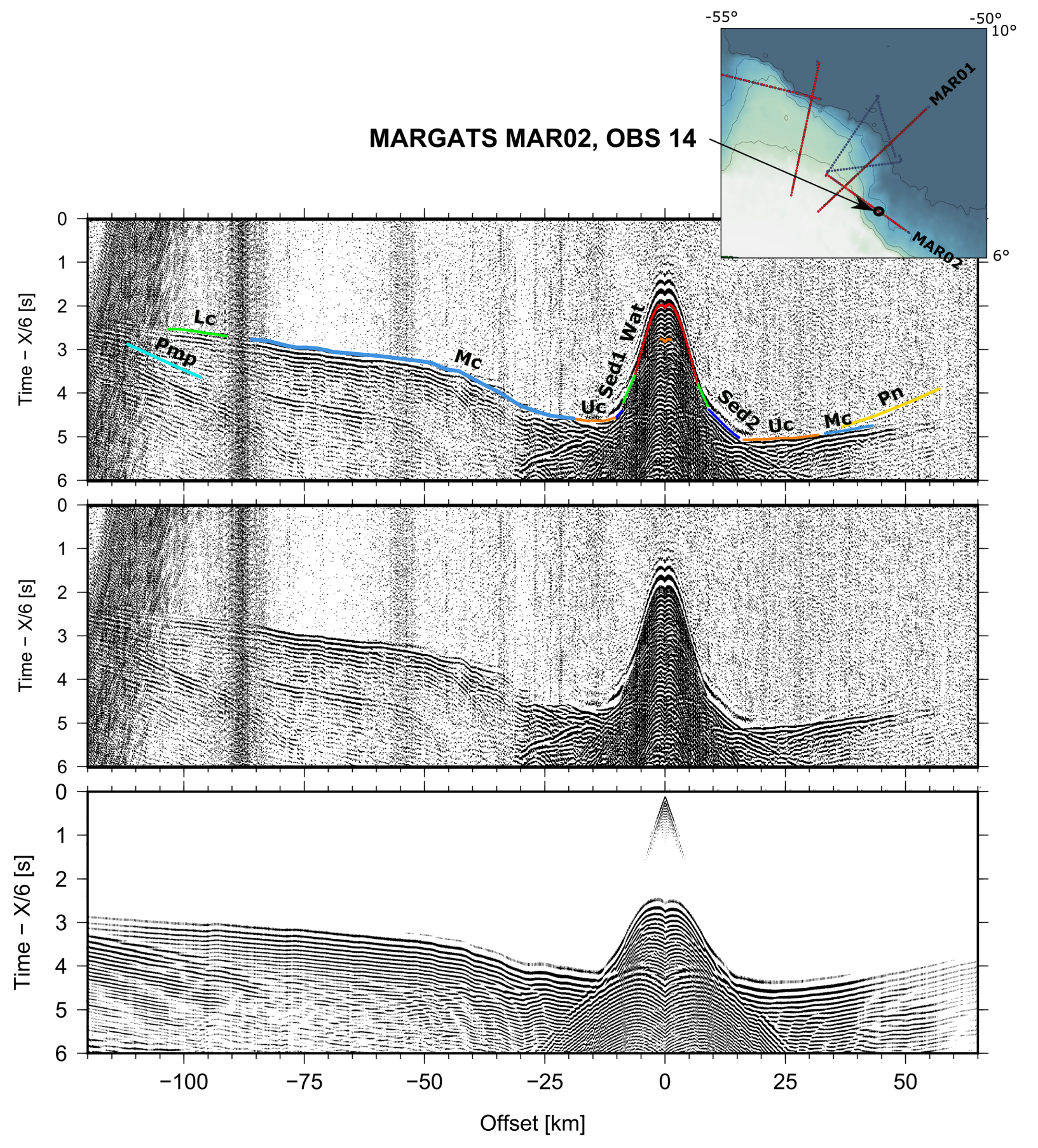

Figure 5 


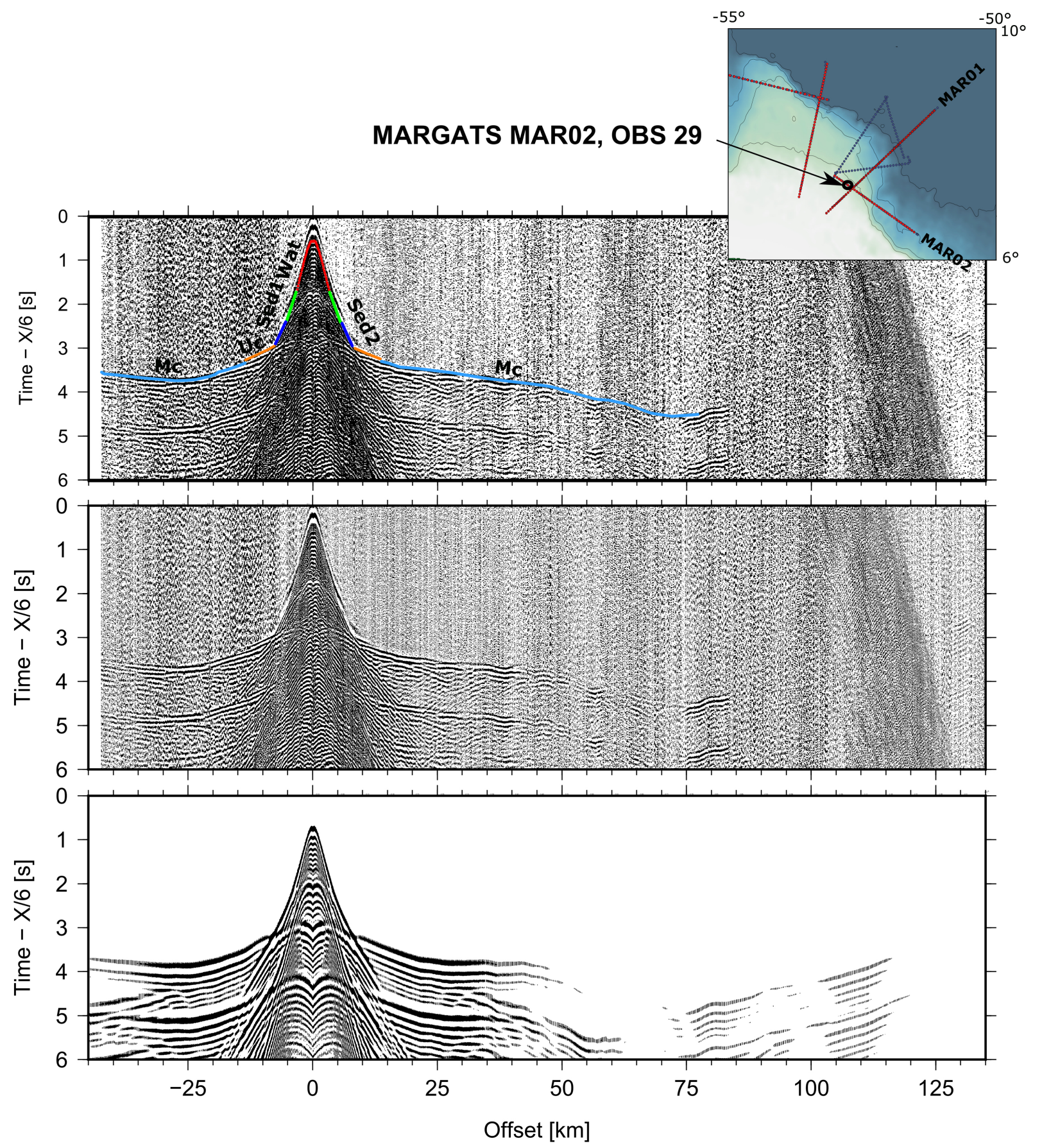

Figure 6 


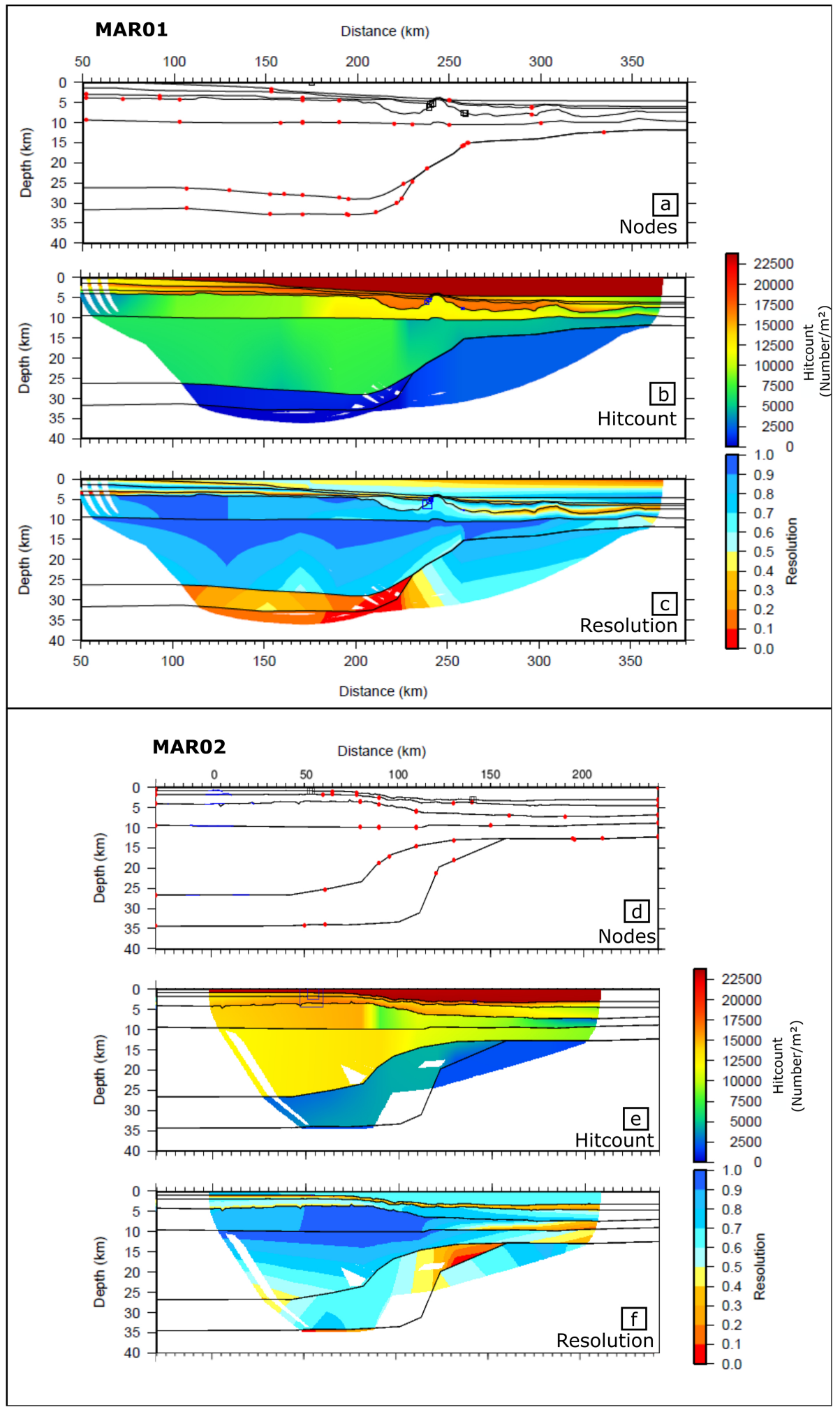




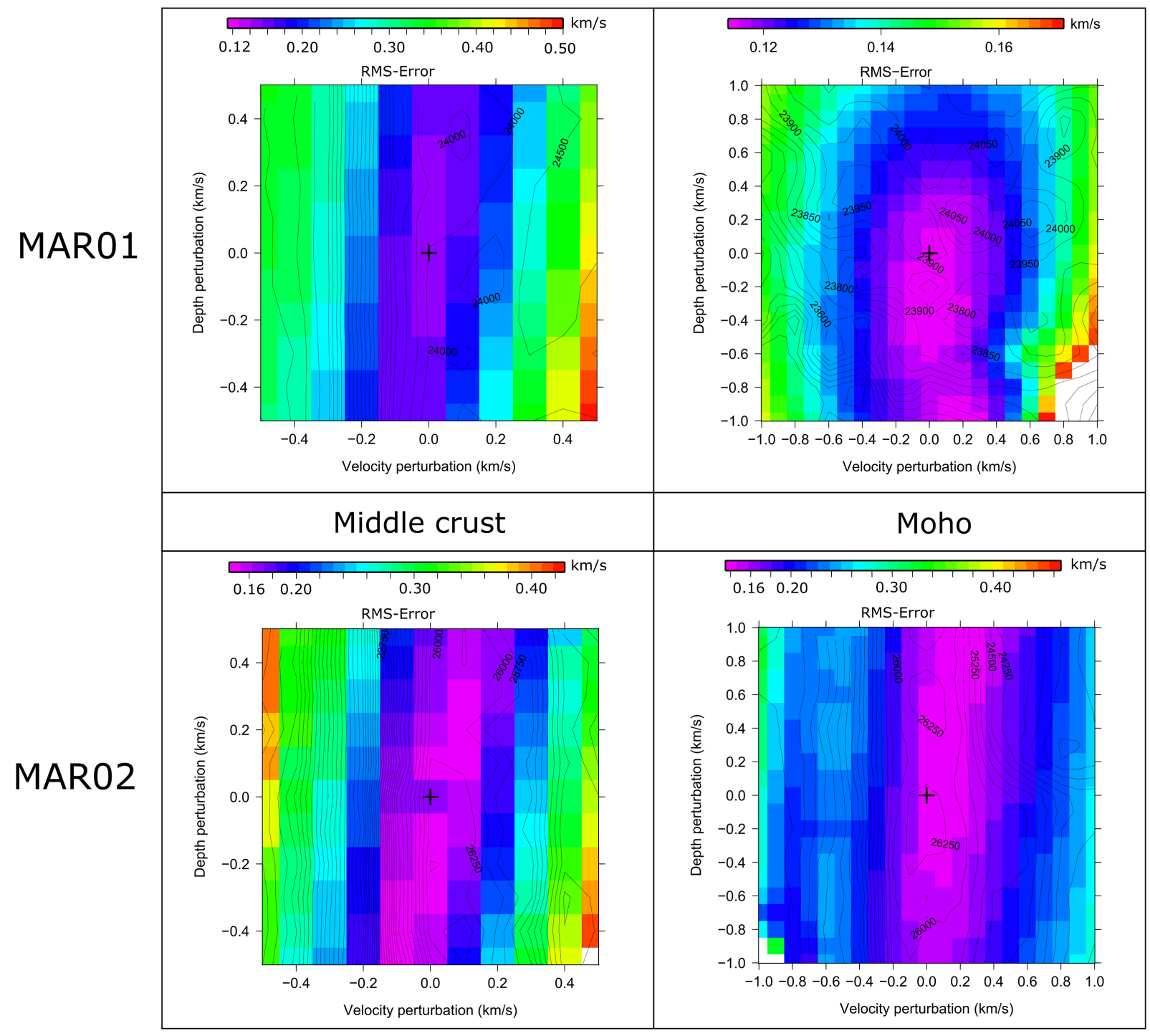

Figure 8 


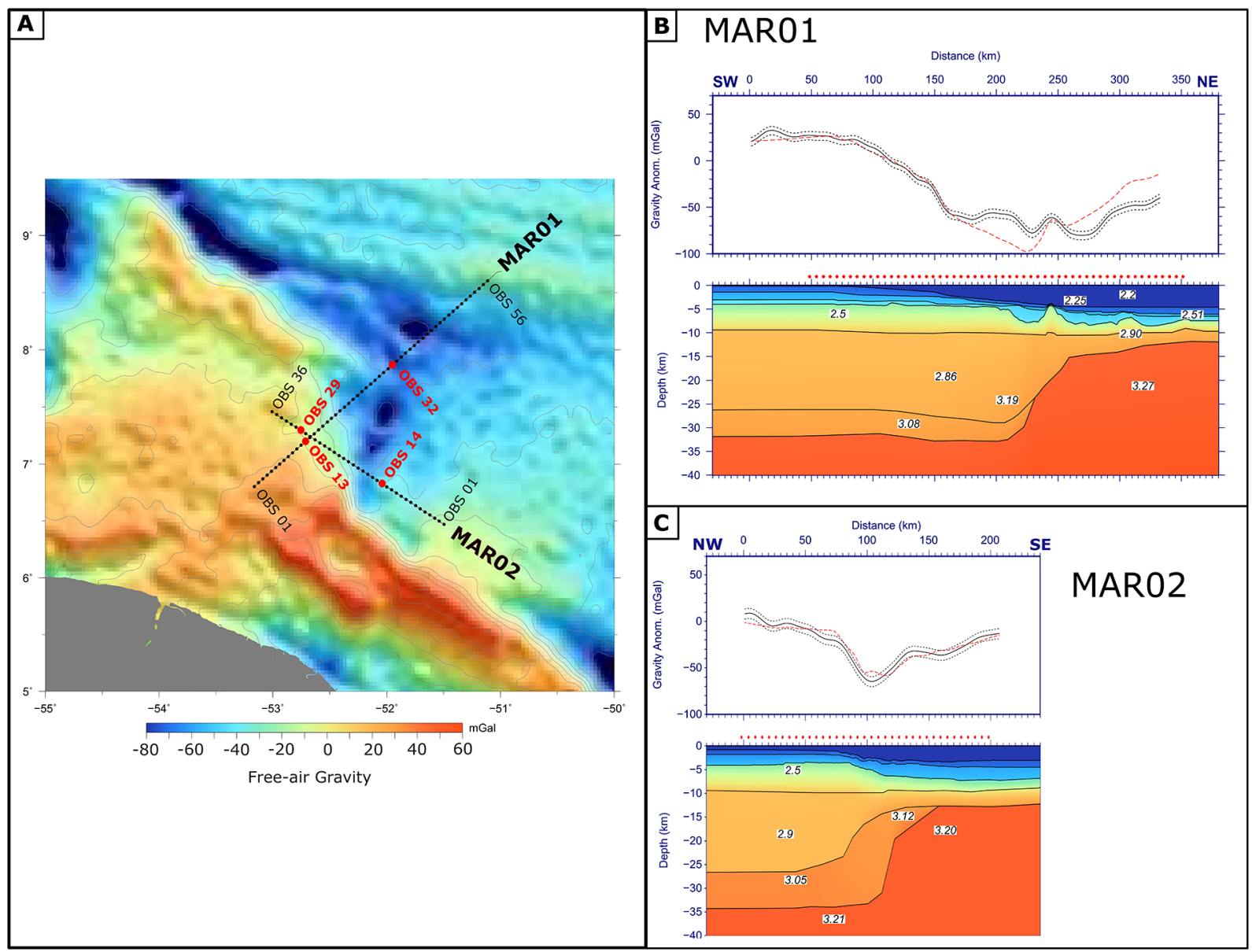

Figure 9 


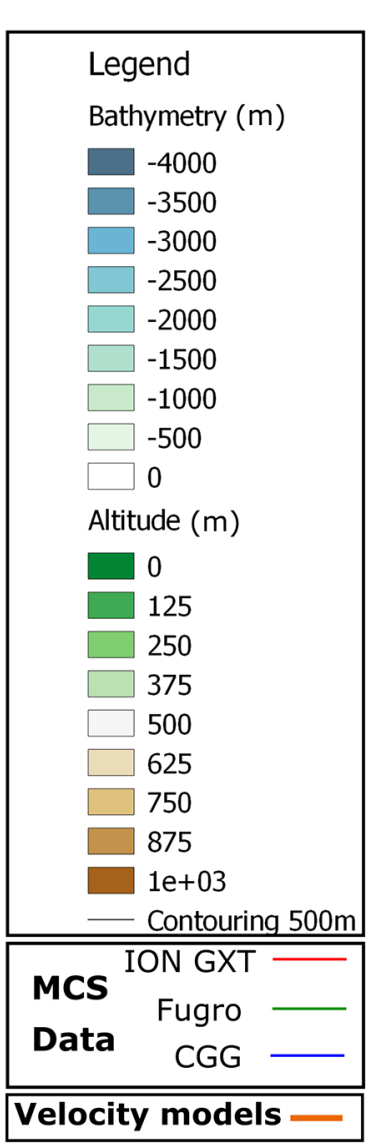

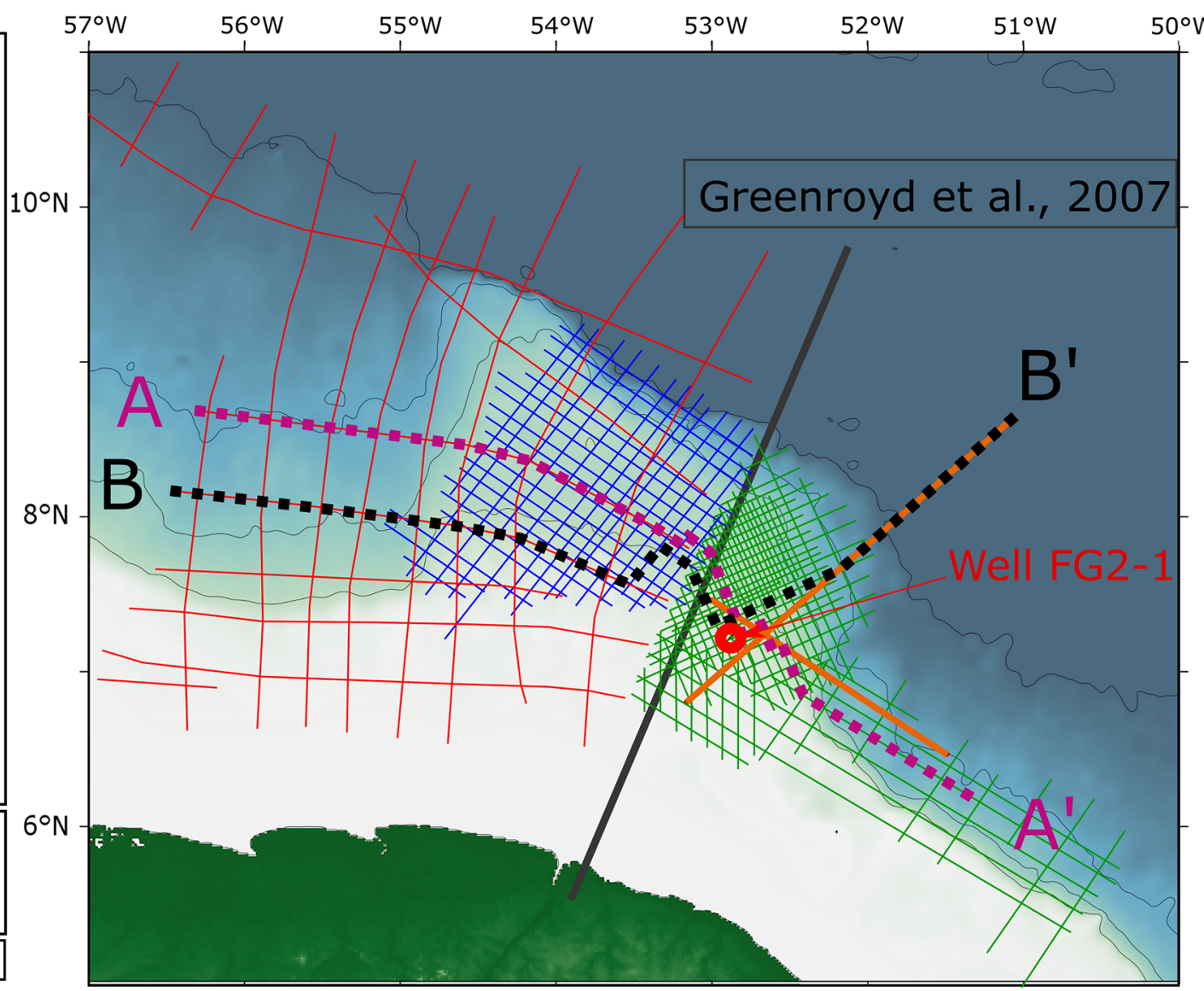

Figure 10 


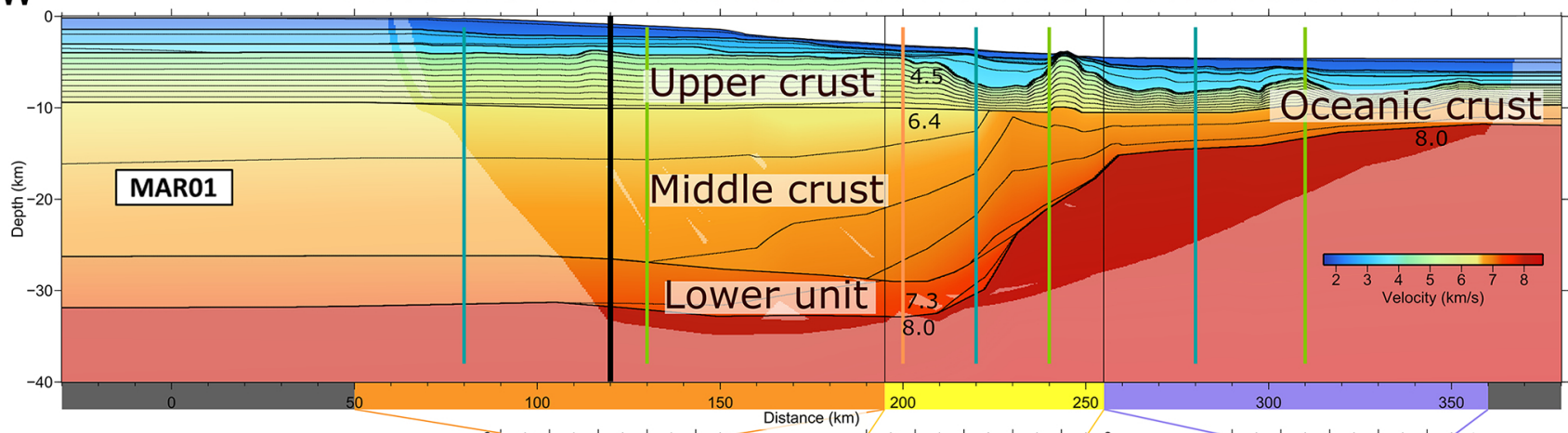

Oceanic crust

(White et al., 1992)

Continental crust (Christensen et al., 1995)
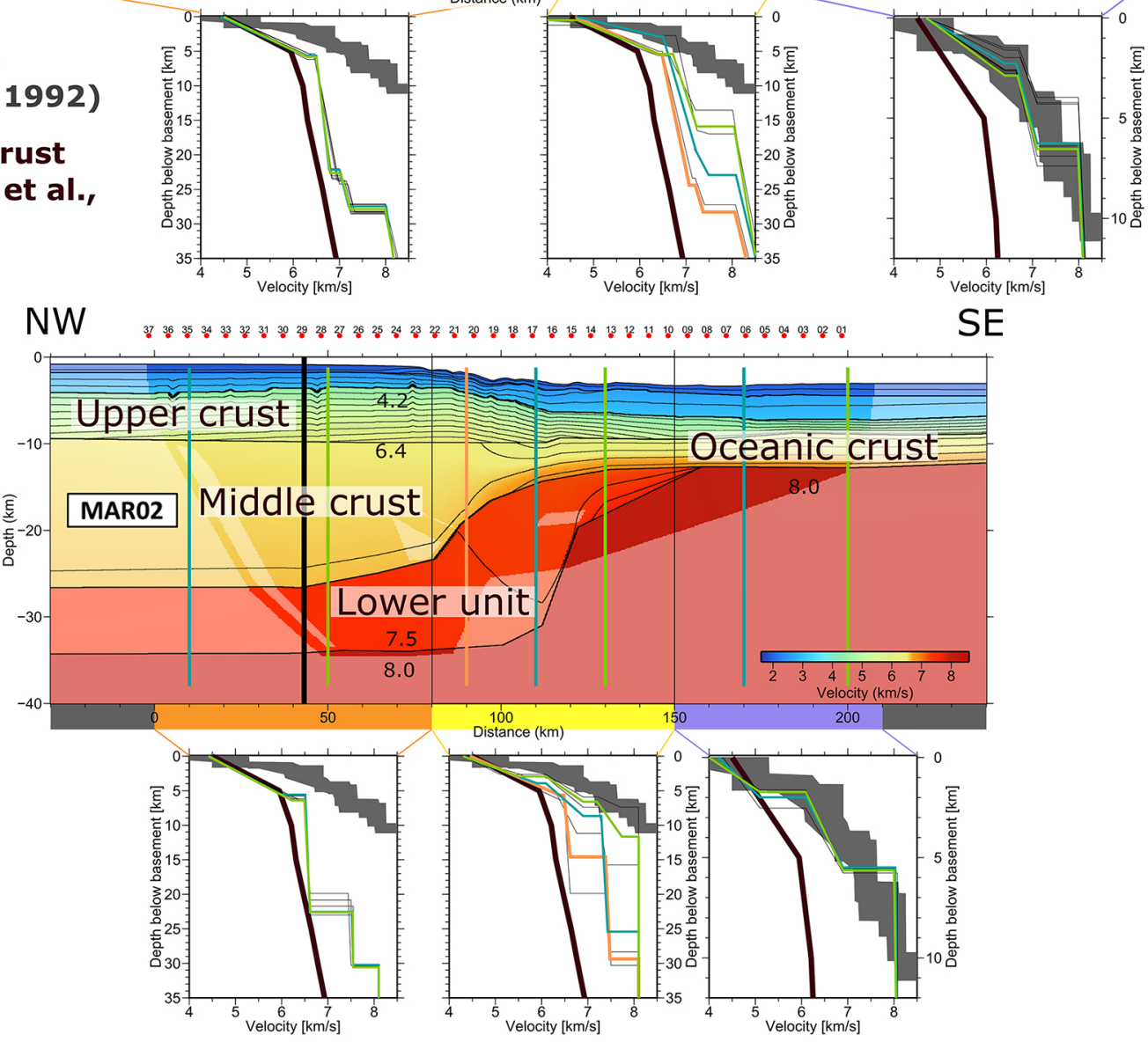

SE

Figure 11 


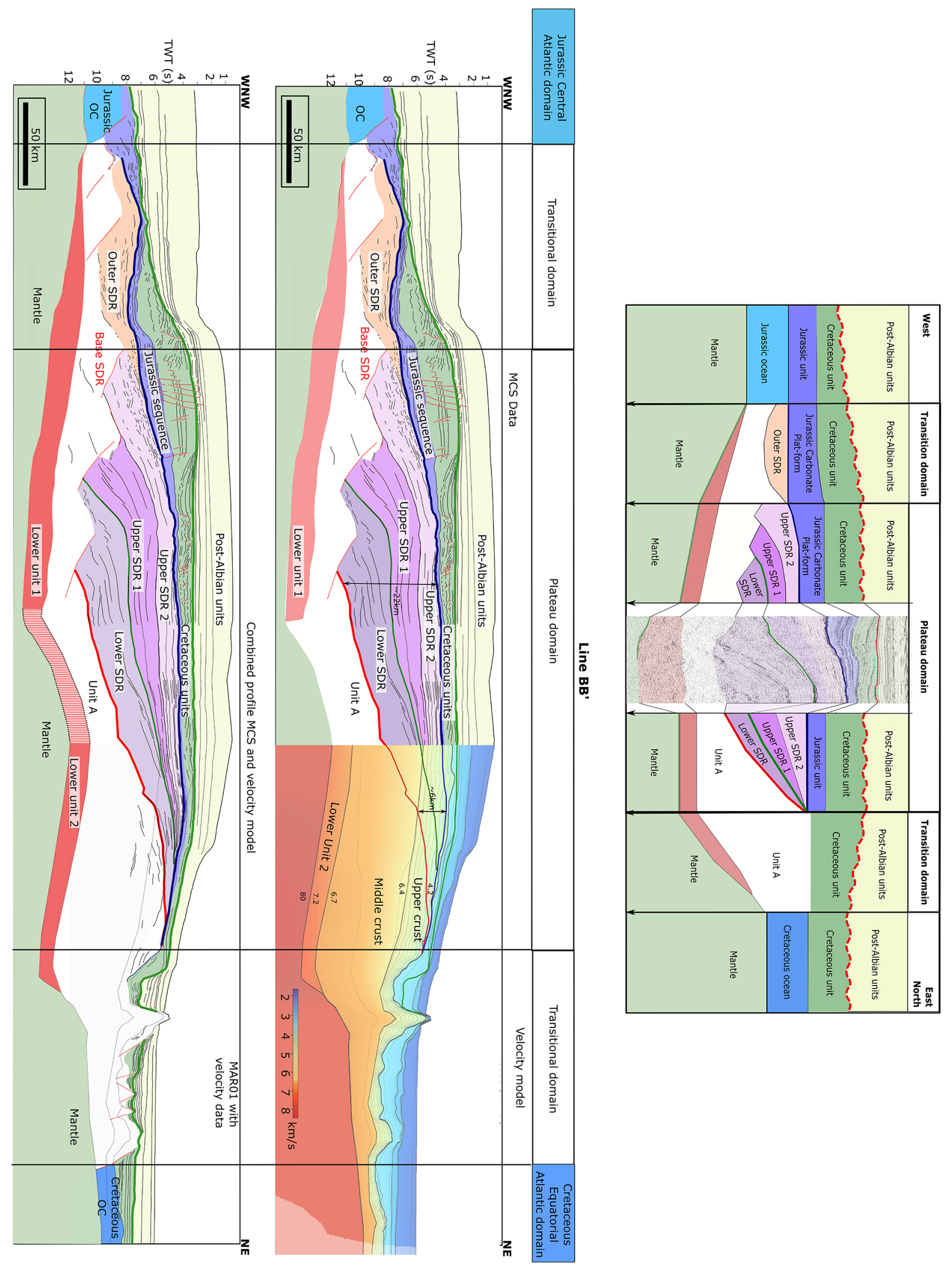

Figure 12 


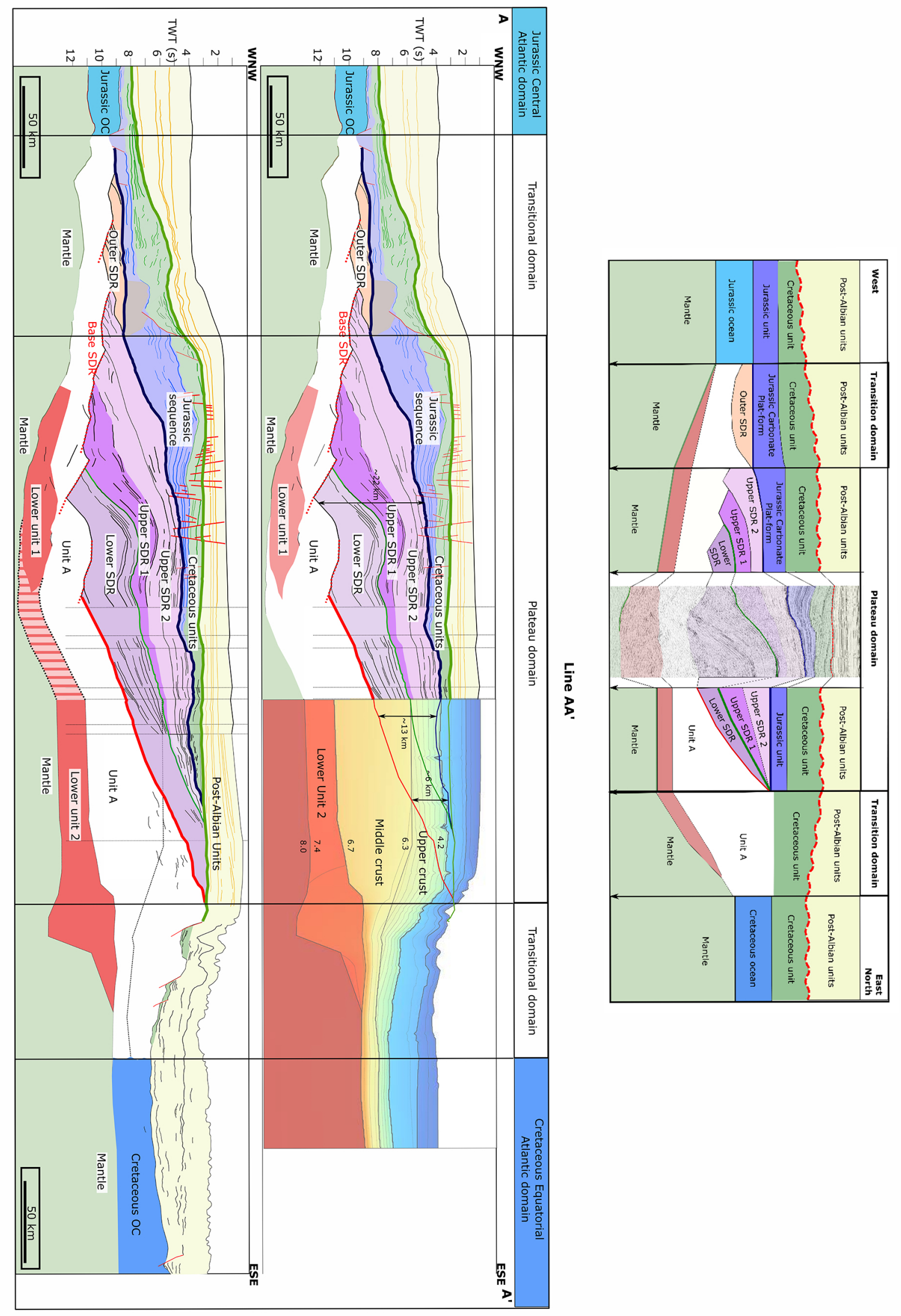



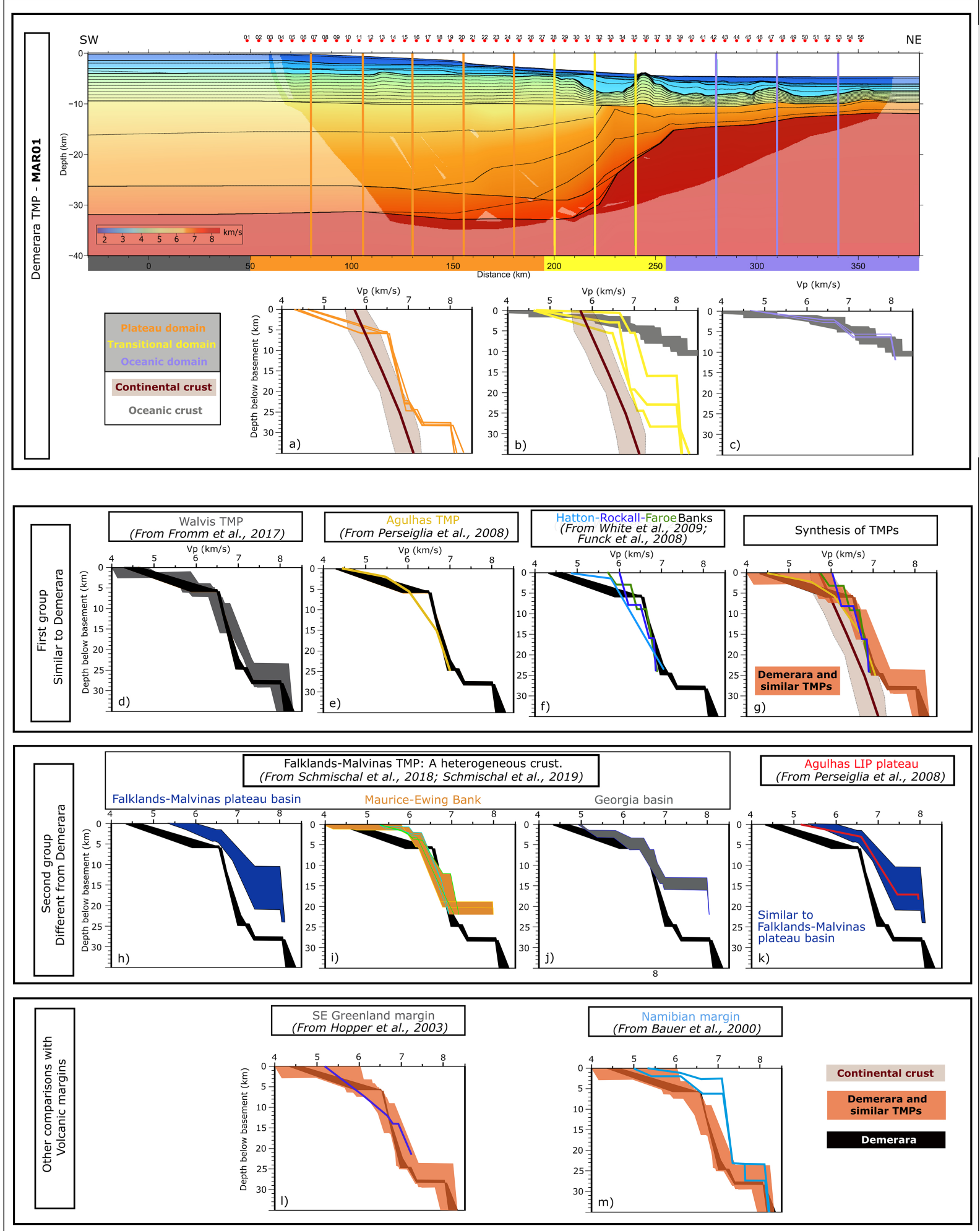
a Demerara - Modified from Reuber et al., 2016.

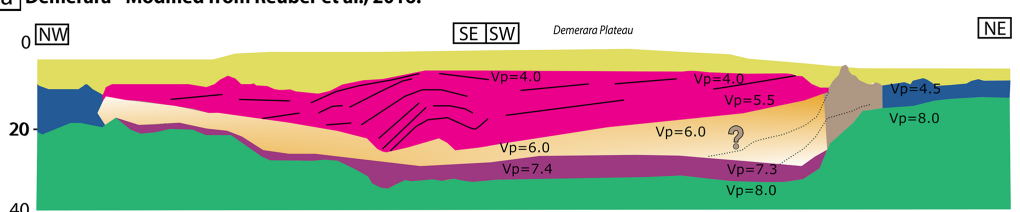

C Walvis Ridge - From Planert et al., 2017; Jegen et al., 2016.

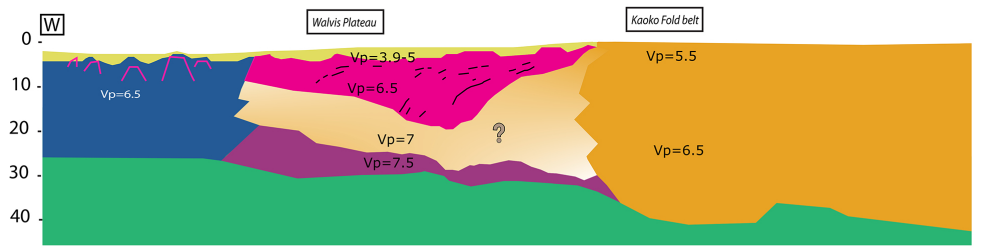

b Hatton Bank - MCS and

WAS data - From

Fowler et al., 1989.

NW $5.0 \mathrm{SE}$

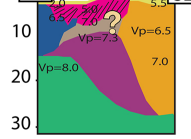

d] Faroe - MCS and WAS data From White et al., 2008.

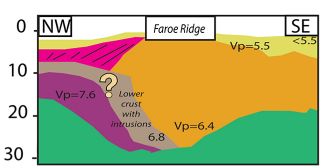

Legend:

Sediments

Continental crust

SDRS's, intrusions, sills, volcanic centers.

Transitional or igneous

Pre-SDR continental crust, reworked by the volcanism

High Velocity Lower Crust

Indifferentiated Oceanic crust

Oceaniclayer2

Oceaniclayer 3

Mantle

e Falklands-Malvinas Plateau, MCS and WAS data - From Schimshal and Jokat, 2018.

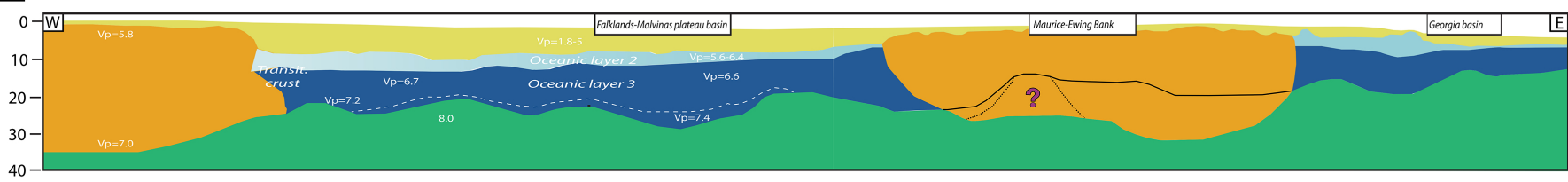

f Pelotas volcanic margin - From Stica et al., 2014.

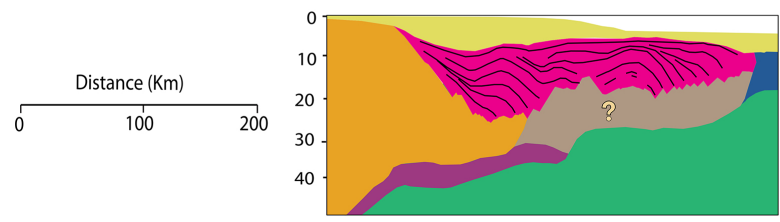

9 Namibian volcanic margin - From Bauer et al., 2000; Fernàndez et al., 2010 .

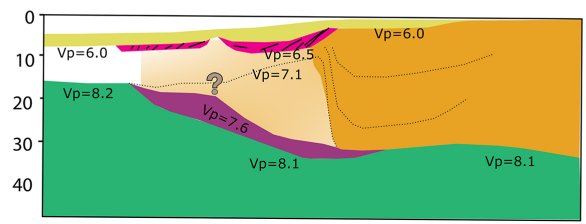

Figure 15 